\title{
CLIMA ORGANIZACIONAL EM UMA MICROEMPRESA DE HOLTER DIGITAL NA REGIÃO DO SUL DE MINAS GERAIS
}

\section{ORGANIZATIONAL CLIMATE IN A DIGITAL HOLTER MICRO ENTERPRISE IN THE SOUTH REGION OF MINAS GERAIS}

\author{
Ana Júlia Melo Prado', Vitória Thainá Siqueira Breves², Sandra de Souza Alves³
}

\author{
Submetido: 27/01/2021 \\ Aprovado: 06/02/2021
}

\section{RESUMO}

Este estudo examina as percepções do clima organizacional dos funcionários e dos gerentes por meio da pesquisa do clima de trabalho de uma pequena empresa no Sul do estado de Minas Gerais. Os dados foram coletados por meio de um questionário de 40 questões objetivas e abertas, submetidas a uma abordagem de análise exploratória e descritiva. A análise inclui todos os 17 membros da empresa. A ferramenta do software Microsoft Excel foi utilizada para mensurar o engajamento no trabalho e o nível de satisfação por meio da aplicação do questionário de clima organizacional. Em relação à implicação prática, os resultados mostram que o relacionamento organizacional e a intercomunicação apresentam um alto índice de satisfação acima de $90 \%$. No entanto, os resultados sugerem que os gerentes devem considerar fatores de motivação, de carreira e de treinamento, proporcionando um ambiente de apoio, de desenvolvimento e de reconhecimento, além do trabalho em equipe. A pesquisa mostrou que o clima organizacional na empresa é favorável, com um percentual de satisfação geral de 92,99\%. Percebe-se a presença de algumas divergências vinculadas a um espaço mais aberto às sugestões e ao trabalho em equipe com a inclusão da percepção de crescimento profissional limitado, porém, mesmo diante das ocorrências, o clima se mostrou favorável.

PALAVRAS-CHAVE: Capital humano. Gestão de pessoas. Voz dos colaboradores.

\begin{abstract}
This study examines employee and manager perceptions of the organizational climate through work climate research of a small enterprise in Brazil. The dates were collected through a questionnaire with 40 objective and descriptive questions and submitted to an exploratory analysis and descriptive approach. The analysis includes all 17 enterprise members. Furthermore, Microsoft Excel software tool was used to measure work engagement and satisfaction level through the application of the organizational climate questionnaire. Regarding the practical implication, results show that organizational relationship and intercommunication have a high level of satisfaction above of $90 \%$. However, the outcomes suggest that managers should consider motivation, career and training factors by providing supportive environment, development and acknowledgment in addition to teamwork. The survey showed that the organizational climate in the company is favorable, with a percentage of overall satisfaction of $92.99 \%$. It is noticed the presence of some gaps linked to a space more open to suggestions and teamwork with the inclusion of limited perception of professional growth, however even with this occurrences the climate proved favorable.
\end{abstract}

KEYWORDS: Human capital. People management. Employees voice.

\footnotetext{
${ }^{1}$ Graduada em Administração de Empresas pela Universidade José do Rosário Vellano - UNIFENAS em 2020, residente no município de Alfenas no sul de Minas Gerais. https://orcid.org/0000-0001-8688-2742 - anahjulia2010@hotmail.com

${ }_{2}^{2}$ Graduada em Administração de Empresas pela Universidade José do Rosário Vellano - UNIFENAS em 2020, residente no município de Alfenas no sul de Minas Gerais. https://orcid.org/0000-0002-9598-6401 - vitoriathaina@hotmail.com

${ }^{3}$ Graduada em Administração e Doutoranda em Agricultura Sustentável pela Universidade José do Rosário Vellano UNIFENAS. Professora na Universidade José do Rosário Vellano. https://orcid.org/0000-0003-4196-2751sandra.alves@unifenas.br
} 


\section{RECIMA21 - REVISTA CIENTÍFICA MULTIDISCIPLINAR}

CLIMA ORGANIZACIONAL EM UMA MICROEMPRESA DE HOLTER DIGITAL NA REGIÃO DO SUL DE MINAS GERAIS Ana Júlia Melo Prado, Vitória Thainá Siqueira Breves, Sandra de Souza Alves

\section{INTRODUÇÃO}

O mercado contingencial é altamente persuasivo e competitivo, pois este está em constante evolução que carece de adaptação e hábil posicionamento estratégico, o que se transfigura em um grande desafio para organizações que buscam Market Share enfático e rendimento suntuoso. Promover um ambiente organizacional harmonioso é um alicerce que contribui para a vantagem competitiva neste contexto contemporâneo, visto que não se restringe apenas à aptidão reacional por parte dos funcionários, mas também a um plano de ação fortificado elaborado pela empresa.

Uma estrutura orgânica desfruta do elemento humano por ser essencial para alcançar bons resultados, utilizando-se de ferramentas que possibilitem maior engajamento por meio do alinhamento de valores e de propósitos, dando abertura a objetivos claros e mensuráveis que impactam a performance do negócio e evitam a negligência de atividades de funcionários com "o jogo político", segundo Greg Mckeown (2015), autor do livro “Essencialismo".

O encontro de ideias é importante para trazer à tona desafios os quais possibilitem que o desenvolvimento humano seja mais palatável para dentro das organizações e assegurem o diálogo corporativo como forma de participação coletiva para o gerenciamento de talentos internos, que personifiquem o sentido da organização de vender valor e não apenas serviços para clientes, dessa maneira, não transferindo responsabilidade exclusivamente para a linha de frente.

O objetivo essencial de uma organização é alcançado de forma conjunta, o que torna notória a importância do investimento em desenvolvimento humano, pois são as pessoas que dão resultado ao negócio. Portanto, é necessário, como ponto de partida, que as empresas possam realizar uma pesquisa de clima organizacional para identificar as variáveis que estão influenciando o comportamento dos gestores e dos colaboradores, levando em consideração que a percepção do contexto corporativo se mostra de maneira individual.

Quando as organizações têm conhecimento da concepção do cenário empresarial atual, medidas de melhorias de gestão aplicadas possuem maior índice de eficácia pela razão de direcionamento do problema a ser solucionado, ocasionando maior nível de satisfação e envolvimento com o propósito da empresa. Diante dessa importância, o objetivo deste estudo foi o de realizar uma pesquisa de clima organizacional numa empresa de Holter digital, para conhecer a percepção dos gestores e dos colaboradores com relação às práticas de gestão e os relacionamentos no ambiente de trabalho. Após as informações coletadas, por meio da aplicação de questionários semiestruturados, pesquisa qualitativa e observacional, demonstrou-se, a partir das análises, se a empresa está num momento de clima organizacional bom ou ruim. 
CLIMA ORGANIZACIONAL EM UMA MICROEMPRESA DE HOLTER DIGITAL NA REGIÃO DO SUL DE MINAS GERAIS Ana Júlia Melo Prado, Vitória Thainá Siqueira Breves, Sandra de Souza Alves

\title{
1 GESTÃO DE PESSOAS - CONTEXTUALIZAÇÃO E CONCEITO
}

Genericamente, compreende-se por Gestão de Pessoas o conjunto de políticas e de práticas necessárias para conduzir os aspectos da gestão administrativa relacionadas aos trabalhadores: planejamento, suprimento, aplicação, desenvolvimento, manutenção e monitoração da força de trabalho dentro da organização/instituição (CHIAVENATO, 1999). A gestão de pessoas já é um assunto tratado desde a época da revolução industrial.

A administração científica desenvolvida por Taylor (1856-1915) traz algumas noções referentes ao conceito. Considerado o pai da administração científica, ele começou seu estudo observando a classe de operários e seu modo de trabalho que não se atentava em capacitações, gerando lucros decrescentes e cada vez mais contratações que eram reflexo da baixa produtividade.

Para Taylor, tratava-se de prescrever exatamente o método de trabalho, indicar as ferramentas e o material utilizado - de acordo com os estudos de movimentos - e estabelecer o tempo dentro do qual a tarefa deveria ser cumprida (graças ao estudo dos tempos). (CHIAVENATO, 1987a). Essa técnica baseava-se em duas etapas, a analítica e a construtiva:

\begin{abstract}
$\mathrm{Na}$ analítica, cada trabalho era dividido no máximo de movimentos possíveis, descartavam-se os movimentos sem sentido, selecionavam-se, mediante a observação do trabalhador mais habilidoso em cada movimento, os métodos mais rápidos e melhores para cada movimento e cronometrava-se e registravase o movimento. Ao tempo registrado, eram adicionadas porcentagens referentes a pausas e interrupções inevitáveis ao grau de novidade que a tarefa representava para o trabalhador e aos períodos de descanso. A fase construtiva envolvia a montagem de uma lista dos movimentos elementares e dos tempos, lista essa que poderia ser utilizada onde fosse possível em outros tipos de trabalho. Além disso, essa última fase permitia considerações sobre melhorias nas ferramentas, nas máquinas, nos materiais, nos métodos e na padronização final de todos os elementos que influenciavam o trabalho ou eram inerentes a ele. (TAYLOR, 1903, p. 149-176, apud WREN, 2007, p. 129)
\end{abstract}

A Teoria Clássica de Fayol complementou o trabalho de Taylor, substituindo a abordagem analítica e concreta de Taylor por uma abordagem sintética, global e universal. Propôs a racionalização da estrutura administrativa e a empresa passou a ser percebida como uma síntese dos diversos órgãos que compõem sua estrutura. A preocupação maior de Fayol é para com a direção da empresa dando ênfase às funções e às operações em seu interior. Estabeleceu os princípios da boa administração, sendo dele a clássica visão das funções do administrador: organizar, planejar, coordenar, comandar e controlar (MATOS,PIRES,2006).

A Teoria Comportamentalista tem sua ênfase mais significativa nas ciências do comportamento e na busca de soluções democráticas e flexíveis para os problemas organizacionais preocupando-se mais com os processos e com a dinâmica organizacional do que com a estrutura. Amplia a discussão sobre a motivação humana com base nas teorias da motivação de Maslow e a teoria sobre os fatores que orientam o comportamento das pessoas de Herzberg. Essa abordagem ganha impulso no início da década de 1980, quando começam a aparecer um conjunto de ideias, de 


\section{RECIMA21 - REVISTA CIENTÍFICA MULTIDISCIPLINAR}

CLIMA ORGANIZACIONAL EM UMA MICROEMPRESA DE HOLTER DIGITAL NA REGIÃO DO SUL DE MINAS GERAIS Ana Júlia Melo Prado, Vitória Thainá Siqueira Breves, Sandra de Souza Alves

experiências e de princípios provenientes do estilo japonês de administração que se preconizou chamar Teoria $Z$ da administração. A teoria $Z$ fundamenta-se nos princípios de: emprego estável; baixa especialização; avaliação permanente do desempenho e promoção lenta; democracia e participação nas decisões; valorização das pessoas (MATOS; PIRES,2006).

O entendimento sobre as teorias dos grandes estudiosos da administração - tais como os estudos expostos anteriormente - são eficazes, pois, por meio deles vieram grandes tópicos que nos dão viés para explanar e identificar como o desenvolvimento humano, alinhado à gestão estratégica são significativos para empregado e empregador.

Segundo Boxall, Pucell e Wrigth (2010), duas vertentes de análises devem ser consideradas quando se trata da gestão de pessoas: questionar o desempenho relativo dos modelos específicos de gestão de recursos humanos em contextos particulares ou da sua contribuição para um melhor desempenho organizacional em relação a outros investimentos organizacionais, tais como novas tecnologias de produção, campanhas publicitárias e aquisições de propriedade; questionar a necessidade do processo de gestão de recursos humanos em si, como e se as organizações poderiam de alguma forma sobreviver ou crescer sem fazer uma tentativa razoável de organização do trabalho e de gestão de pessoas.

A Teoria do Desenvolvimento Organizacional surge de um conjunto de ideias a respeito do ser humano, da organização e do ambiente na perspectiva de propiciar o crescimento e o desenvolvimento organizacional, de acordo com suas potencialidades. Volta-se para estratégias organizacionais planejadas por meio de modelos de diagnóstico, de intervenção e de mudanças envolvendo modificações estruturais ao lado de modificações comportamentais para melhorar a eficiência e a eficácia das empresas (MATOS, PIRES,2006).

\subsubsection{Relevância da competência e do conhecimento ao fator humano}

As organizações têm suas engrenagens para que haja funcionalidade. Cada departamento da empresa é fundamental para que ocorra um trabalho que possa ser prestigiado por seus usuários. Por isso o fator humano deve estar alinhado com a organização, pois são as pessoas que executam esse trabalho e fazem com que a qualidade no atendimento não seja apenas teoria, mas sim uma prática executada.

"A organização é um arranjo sistemático de duas ou mais pessoas que cumprem papéis formais e compartilham um propósito comum" (ROBBINS, 2002, p.31).

Por essa razão, as pessoas que trabalham na empresa devem ser consideradas recursos primordiais que, com suas crenças, valores, experiências, podem agregar valores e ser transformados em lucros, em produtividade e em boa fama da organização.

O capital intelectual é a soma do conhecimento de todos em uma empresa, o que the proporciona vantagem competitiva. Ao contrário dos ativos, com os quais empresários e contadores 


\section{RECIMA21 - REVISTA CIENTÍFICA MULTIDISCIPLINAR}

CLIMA ORGANIZACIONAL EM UMA MICROEMPRESA DE HOLTER DIGITAL NA REGIÃO DO SUL DE MINAS GERAIS

Ana Júlia Melo Prado, Vitória Thainá Siqueira Breves, Sandra de Souza Alves

estão familiarizados - propriedade, fábricas, equipamentos, dinheiro -, o capital intelectual é intangível. "O capital humano é a fonte de inovação e renovação dentro da empresa" (STEWART, 1998, p. 68). Desse modo, são as pessoas a fonte primordial do bom funcionamento, são estas que agregam valor, geram lucros e que constroem a boa reputação da organização. (STEWART, 1998,p. 5, apud MOREIRA, VIOLIN, SILVA,2014, p.301).

Utilizando-se do conceito abordado por Stewart (1998), o capital intelectual é avaliado como a fonte de riqueza tanto para os indivíduos quanto para as organizações, um recurso de propriedade tanto de um quanto de outra (MOREIRA, VIOLIN, SILVA,2014).

\section{CLIMA ORGANIZACIONAL}

O clima possui princípio intangível por interferir na esfera psicológica particular de cada organização. Os fatores determinantes do clima são cruciais para que se tenha ganho de eficiência operacional que, na realidade, necessita de disposições econômicas e estruturais, tais como: formação, capacitação e treinamento de toda equipe, além de aspectos quantitativos, como a remuneração. Essas variáveis de entrada auxiliam no aumento da capacidade dos colaboradores pelo ganho de produtividade, a qual está vinculada a uma variável dependente. (CHIAVENATO, 2015).

O desempenho do capital humano, assim como a qualidade de vida no ambiente corporativo, está atrelado ao comportamento dos funcionários, os quais são expostos a estímulos oriundos do clima organizacional, ou seja, as atitudes advêm inteiramente da influência interna da empresa. (SIQUEIRA,2008).

As percepções subjetivas provenientes do clima organizacional são responsáveis por atuarem de forma direta e indireta dentro do ambiente de trabalho. Isso significa dizer que influenciam no comportamento e, consequentemente, na motivação do grupo em foco (ALEXANDRE, 2018). Diante disso, vale ressaltar que um clima favorável é diretamente proporcional à geração de satisfação, pois causa maior envolvimento do funcionário e, por sua vez, sucede em resultados positivos para ambos os lados. No entanto, o clima e a satisfação são de naturezas distintas, uma vez que, enquanto o clima está relacionado com a cognição do ato de percepção, a satisfação se conecta com elementos afetivos dos aspectos presentes ou ausentes do ambiente de trabalho, suprindo necessidades pessoais (SIQUEIRA,2008).

Ademais, é importante salientar que o executivo possui condições de atuar ativamente no clima de tal modo que fique mais promíscuo, operando, desse modo, elementos das variáveis de entrada que produzam resultados na organização. Além disso, ocorre a possibilidade de utilizar indicadores que medem o clima organizacional, pois, por meio do diagnóstico, a empresa se certifica do comprometimento dos colaboradores com o objetivo essencial da estrutura corporativa (CHIAVENATO, 2015). A figura seguinte demonstra de maneira simplificada toda a sistematização. 


\section{RECIMA21 - REVISTA CIENTÍFICA MULTIDISCIPLINAR}

CLIMA ORGANIZACIONAL EM UMA MICROEMPRESA DE HOLTER DIGITAL NA REGIÃO DO SUL DE MINAS GERAIS Ana Júlia Melo Prado, Vitória Thainá Siqueira Breves, Sandra de Souza Alves

FIGURA 1: DETERMINANTES DO CLIMA

\begin{tabular}{|c|}
\hline Variáveis de entrada \\
Estrutura organizacional \\
Cultura organizacional \\
Condições econômicas \\
Ênfase no engajamento \\
Oportunidade de participação \\
Significado do trabalho \\
Construção da equipe \\
Estilo de liderança \\
Reconhecimento \\
Incentivos e recompensas
\end{tabular}

ariáveis de entrada

Condições econômicas

Significado do traba

Incentivos e recompensas

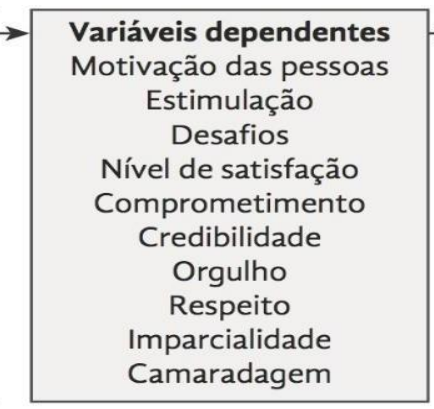

Fonte: Chiavenato (2015)

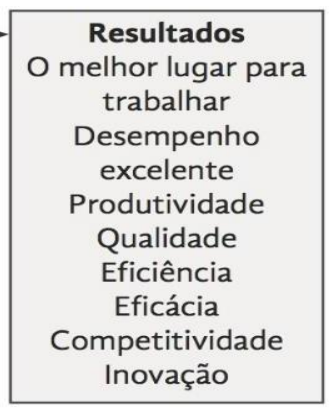

Resultados
O melhor lugar para
trabalhar
Desempenho
excelente
Produtividade
Qualidade
Eficiência
Eficácia
Competitividade
Inovação

(1)

\subsection{Importância da pesquisa de clima organizacional}

A pesquisa de clima organizacional, usualmente aplicada por meio de questionário préestruturado, é responsável por diagnosticar a percepção dos colaboradores junto com sua satisfação diante do ambiente de trabalho estabelecido no momento da coleta de dados, o que torna importante o monitoramento regular para aferir a evolução do processo do clima no ambiente. (JOHANN, 2013).

Ainda de acordo com Johann, o feedback recolhido se torna vital para que haja uma avaliação dos aspectos que estão interferindo no clima, com o objetivo de realizar a manutenção de elementos para um bom nível de satisfação. Diante da relevância do diagnóstico, pósteros procedimentos elaborados são mais assertivos por atingirem a natureza do problema desavisto. Isso implica dizer que influencia proporcionalmente no estabelecimento de um ambiente favorável de trabalho, resultando em maior índice de desempenho e de desenvolvimento dos colaboradores(MEZA, 2015).

A melhora de desenvoltura dos funcionários advinda da implantação propícia da esfera organizacional ampara na obtenção de objetivos essenciais, além de harmonizar interesses entre alta direção e trabalhadores, ou seja, a apreensão da coparticipação de metas, valores, missão e visão é processada com maior facilidade. (ALEXANDRE,2018).

\section{DESENVOLVIMENTO HUMANO ORGANIZACIONAL- CONTEXTUALIZAÇÃO E CONCEITO}

O elemento humano dentro da organização não é uma simples peça repositora, pois esse insumo é algo complexo, principalmente porque impacta consideravelmente na cadeia de produção de bens ou de serviços (PASBAN \& NOJEDEH, 2016).

Sabendo disso, atualmente, as empresas têm procurado mudar a mentalidade de um sistema estrutural primordialmente mecânico para se posicionar estrategicamente da melhor maneira no mercado, utilizando-se da economia do conhecimento, a qual se destina a potencializar os benefícios de estimular as habilidades, a criatividade e as competências de todo capital humano dentro da 


\title{
RECIMA21 - REVISTA CIENTÍFICA MULTIDISCIPLINAR
}

CLIMA ORGANIZACIONAL EM UMA MICROEMPRESA DE HOLTER DIGITAL NA REGIÃO DO SUL DE MINAS GERAIS Ana Júlia Melo Prado, Vitória Thainá Siqueira Breves, Sandra de Souza Alves

empresa. (BEYER \& SOLER, 2019). O valor do elemento humano é monumental em relação aos aspectos materiais da empresa, de acordo com Stiles e Kulvisaechana:

\begin{abstract}
A ênfase das organizações no capital humano é baseada na visão de que o valor de mercado das organizações depende mais de ativos intangíveis, especialmente capital humano, do que de ativos tangíveis. Empregar e manter os melhores funcionários da organização fazem parte deste acordo. As organizações devem aumentar o nível de aprendizado organizacional, aumentar o nível das habilidades dos funcionários, incentivando-os e proporcionando uma atmosfera onde o conhecimento é criado, compartilhado e aplicado e o aprendizado se torna um hábito. (STILES \& KULVISAECHANA, 2003, apud PASBAN \& NOJEDEH, 2016, p. 251)
\end{abstract}

A aplicabilidade de ferramentas de aprendizagem constitui a essencialidade do desenvolvimento humano na organização. Por meio do aperfeiçoamento contínuo das qualidades existentes do funcionário, é possível obter inovação para lidar com problemas cotidianos. Como o desenvolvimento humano nas organizações que o adotam deve ser efetivo, torna-se fundamental o planejamento das ações de capacitação e de treinamentos que serão necessários em determinados períodos.

\subsection{Capacitação e treinamento}

O treinamento e a capacitação são métodos de atividades pelos quais as organizações aprimoram as habilidades técnicas dos funcionários, melhorando, dessa maneira, a qualidade dos produtos e dos serviços oferecidos.

Dessler (2003) define o treinamento como sendo um conjunto de táticas responsáveis por alavancar as habilidades de todos os colaboradores para a obtenção de melhor desempenho organizacional, além de ser considerado como educação complementar para a melhoria de qualidade na capacidade de comunicação e na tomada de decisões, tendo em vista a necessidade de novos procedimentos à medida que a tecnologia do meio inserido avança. De acordo Peloso e Yonemoto (2010, p.10):

Os métodos de treinamento também têm acompanhado o desenvolvimento das técnicas de gestão de pessoas. Os treinamentos têm deixado de ser apenas teóricos e técnicos, para assumirem uma metodologia que proporcione maior aplicabilidade dos conceitos que foram abordados durante o processo de capacitação.

É profícuo salientar que o desenvolvimento humano e o treinamento são partes sinérgicas que atuam em conjunto. Peloso e Yonemoto (2010, p.11) dizem que: "O desenvolvimento do capital humano é uma capacitação mais ampla e aprofundada dos colaboradores, e que tende a gerar resultados ainda mais satisfatórios do que os obtidos através do simples treinamento". Sendo assim, atualmente, a aprendizagem aplicada, por meio de técnicas, é um novo artifício de gestão das empresas para que se alcance um melhor índice de desempenho. Ao longo do tempo, o paradigma ganhou maturidade por parte da organização, como visto na tabela seguinte. 


\section{RECIMA21 - REVISTA CIENTÍFICA MULTIDISCIPLINAR}

CLIMA ORGANIZACIONAL EM UMA MICROEMPRESA DE HOLTER DIGITAL NA REGIÃO DO SUL DE MINAS GERAIS Ana Júlia Melo Prado, Vitória Thainá Siqueira Breves, Sandra de Souza Alves

TABELA 1: MUDANÇAS DE PARADIGMAS AO LONGO DO TEMPO.

\begin{tabular}{|c|c|c|}
\hline Conceito & $\begin{array}{l}\text { Antigo paradigma de } \\
\text { treinamento }\end{array}$ & $\begin{array}{l}\text { Paradigma da aprendizagem do século } \\
\text { XXI }\end{array}$ \\
\hline Conteúdo & $\begin{array}{c}\text { Atualizar qualificações } \\
\text { técnicas }\end{array}$ & $\begin{array}{c}\text { Desenvolver competências básicas do } \\
\text { ambiente de negócios }\end{array}$ \\
\hline Frequência & Evento único & Processo contínuo de aprendizagem \\
\hline Meta & $\begin{array}{l}\text { Desenvolver o estoque de } \\
\text { qualificações do indivíduo }\end{array}$ & $\begin{array}{c}\text { Solucionar problemas empresariais reais } \\
\text { e melhorar o desempenho no trabalho }\end{array}$ \\
\hline
\end{tabular}

Fonte: Adaptação Meister (1999).

Segundo Chiavenato (2014), as empresas usam de diversas técnicas de treinamento e de capacitação com o objetivo de mudar o comportamento conservador dos funcionários para atitudes mais dinâmicas e criativas que priorizem o trabalho em equipe ao desenvolver habilidades e transmitir conhecimento. Nesse sentido, o treinamento deve ser algo contínuo e sem interrupção, utilizando-se do processo de capacitação dos colaboradores presentes. Ainda segundo o autor, os programas de treinamento são responsáveis por esclarecer e por alinhar os objetivos da organização por meio do compartilhamento de informações resignadas à política de procedimento de atuação, tais como missão e valores. Alguns programas focam em habilitar os colaboradores. Outros, em implantar atitudes para lidar com o cliente interno e externo ou elevar a capacidade dos funcionários no processo de tomada de decisão. As diversas dimensões do treinamento estão listadas na figura a seguir.

FIGURA 2: TIPOS DE MUDANÇAS DECORRENTES DO TREINAMENTO. 


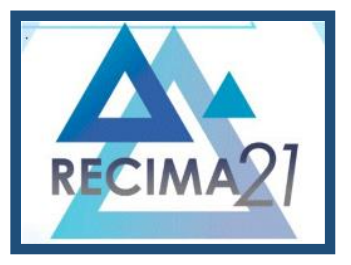

\section{RECIMA21 - REVISTA CIENTÍFICA MULTIDISCIPLINAR}

CLIMA ORGANIZACIONAL EM UMA MICROEMPRESA DE HOLTER DIGITAL NA REGIÃO DO SUL DE MINAS GERAIS

Ana Júlia Melo Prado, Vitória Thainá Siqueira Breves, Sandra de Souza Alves

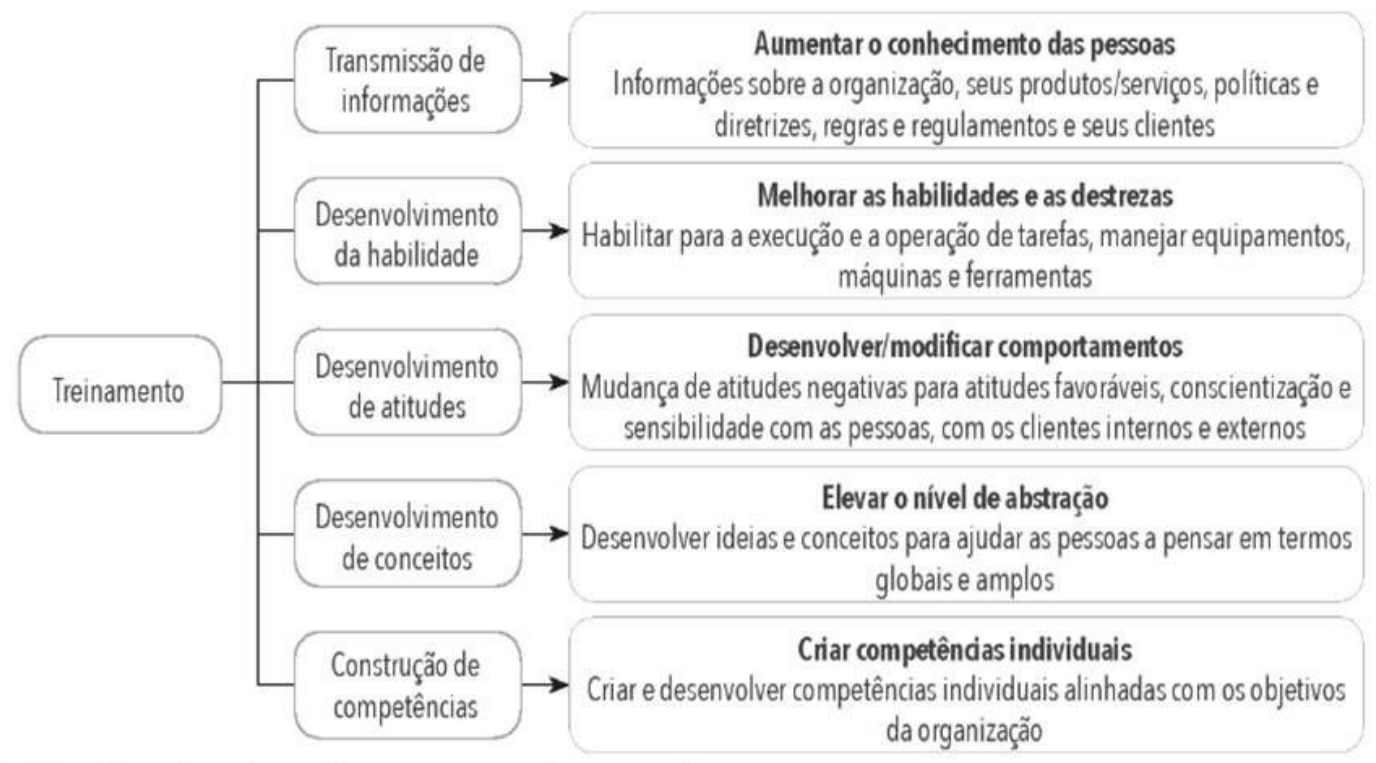

Fonte: Chiavenato (2014)

Dessa maneira, as competências trabalhadas em conjunto são responsáveis pela obtenção de melhor eficiência e eficácia. Todavia, é de suma importância recapitular que desenvolvimento humano e treinamento (T\&D) são partes complementares. Enquanto o treinamento é direcionado para lograr uma performance satisfatória para o cargo no presente, o desenvolvimento de pessoas focaliza no know-how da demanda futura.

\subsection{As quatro dimensões em DRH no desempenho do funcionário}

O Desenvolvimento de Recursos Humanos é uma peça-chave para garantir melhores resultados em atividades referentes à aprendizagem em níveis individuais, grupais e organizacionais, o que promove o desenvolvimento e o treinamento para alcance de objetivos estratégicos. A proficiência desse posicionamento é garantida pela mudança de comportamento por meio desinergias que englobam as necessidades de todos dentro da empresa a partir da aplicação de dimensões práticas e políticas em DRH (DIAS, 2017).

Partindo desse ponto, os aspectos em DRH devem serem analisados conjuntamente no processo para que haja melhora na performance dos funcionários. Segundo Sung e Choi (2014), as quatro dimensões, que englobam concepções da gerência e de funcionários, se dividem em parâmetros quantitativos: (I) investimento de recursos em $\mathrm{DRH}$, que caracteriza a própria forma gestão; (II) exposição dos funcionários a $\mathrm{DRH}$, que se refere à intensidade em que os colaboradores estão destinados ao treinamento e desenvolvimento das atividades planejadas. E por último, em parâmetros qualitativos, os quais são: (III) apoio gerencial ao $\mathrm{DRH}$, que determina o 


\section{RECIMA21 - REVISTA CIENTÍFICA MULTIDISCIPLINAR}

CLIMA ORGANIZACIONAL EM UMA MICROEMPRESA DE HOLTER DIGITAL NA REGIÃO DO SUL DE MINAS GERAIS Ana Júlia Melo Prado, Vitória Thainá Siqueira Breves, Sandra de Souza Alves envolvimento da alta gerência ao dar suporte a progressão em $\mathrm{RH}$, e (IV) benefícios percebidos do $\mathrm{DRH}$, que se destina ao entendimento da pertinência, por parte dos funcionários, das atividades promovidas pelo $\mathrm{RH}$.

\section{QUADRO 1-QUATRO DIMENSÕES DO DRH}

\begin{tabular}{|c|c|c|}
\hline Fator & Quantitativo & Qualitativo \\
\hline $\begin{array}{c}\text { Perceptiva do } \\
\text { funcionário }\end{array}$ & Exposição dos & Benefícios \\
funcionários à HRD & percebidos \\
\hline $\begin{array}{c}\text { Perceptiva da } \\
\text { gerência }\end{array}$ & Investimento em & Apoio gerencial à \\
recursos em DRH & $\mathrm{DRH}$ \\
\hline
\end{tabular}

Fonte: Prado e Breves (2020)

O desenvolvimento do capital humano efetivo é resultado das interações correntes das dimensões em DRH. Por esse motivo, aumentar apenas o índice T\&D para engajar funcionários a alcançar melhores resultados não garante o alcance dos benefícios de DRH. É necessário equilibrar as propriedades qualitativas e quantitativas para maximizar o desempenho dos colaboradores. Desse modo, as implicações vão além de um apoio financeiro, uma vez que as abordagens devem ser eficientes para convencer aos funcionários do envolvimento estratégico dos gestores e dos líderes e da importância de aderir à aprendizagem com comprometimento ao DRH. Os esforços sinérgicos aumentam a competência dos colaboradores, acarretando em um melhor rendimento para a organização (SUNG \& CHOI, 2014). Dito isso, o aumento progressivo das habilidades tem impacto diretamente na administração da vantagem competitiva do elemento humano dentro do ambiente.

\subsection{Geração de vantagem competitiva por meio do elemento humano}

É necessário realçar a importância do T\&D para fortalecer os pontos fortes de cada funcionário, elevando, portanto, a qualificação de toda a equipe. Segundo Peloso e Yonemoto (2010, p.10-22), é crucial que o treinamento e a capacitação abranjam todos os colaboradores da organização da base ao topo da hierarquia, visando à obtenção de uma resposta efetiva diante de tendências futuras e, ainda, estabelecendo um diferencial de capital humano dentro da empresa. Por conseguinte, é evidente que o processo não deve ser encarado como um custo, pois, quanto maior o investimento no capital humano, maior será o retorno para a instituição, o que será uma fonte de vantagem competitiva.

Segundo Armstrong (2008, apud PASBAN \& NOJEDEH, 2016), a vantagem competitiva é obtida por meio da retenção de funcionários talentosos e qualificados para a composição de um forte time, desse modo, havendo distinção em relação aos componentes pertencentes aos da corrente em questão, levando em consideração a essencialidade de prestar serviços ao cliente de forma flexível e criativa para um bom desempenho organizacional. 


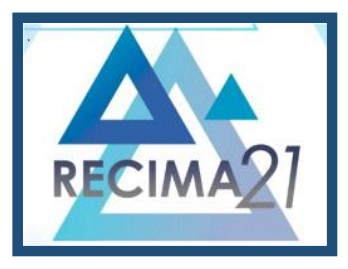

\section{RECIMA21 - REVISTA CIENTÍFICA MULTIDISCIPLINAR}

CLIMA ORGANIZACIONAL EM UMA MICROEMPRESA DE HOLTER DIGITAL NA REGIÃO DO SUL DE MINAS GERAIS

Ana Júlia Melo Prado, Vitória Thainá Siqueira Breves, Sandra de Souza Alves

Ademais, o elemento humano é algo difícil de ser copiado, devido a sua complexidade, pois demanda investimento em longo prazo, medido por indicadores qualitativos por intermédio de medidas implantadas. Os autores Stadler e Pampolini (2014) explicam as dimensões, as quais são:

- Proporcionar segurança às pessoas no emprego;

- Alta seletividade na admissão, para obter alinhamento com a cultura da empresa;

- Remuneração elevada, para atrair pessoas mais qualificadas;

- Incentivos financeiros e não financeiros, como reconhecimento, meritocracia, ambiente saudável;

- Participação acionária e nos lucros promove o comprometimento;

- Partilhar informações, ideias, inovações e estratégias;

- Descentralização e empowerment;

- Treinamento e desenvolvimento de habilidades;

- Igualdade simbólica, através da redução de status dentro da organização;

- Prioridades para promoções internas;

- Perspectivas de longo prazo, a vantagem competitiva por meio de pessoas requer investimento;

- Alinhamento da cultura organizacional.

\section{MATERIAL E MÉTODOS}

Realizou-se uma pesquisa de abordagem descritiva e natureza quantitativa do problema, desenvolvida por meio de um levantamento realizado junto aos profissionais de uma empresa de Holter digital localizada na região Sul de Minas Gerais. Todos os procedimentos utilizados nesta pesquisa foram cumpriram as normas do Comitê de Ética em Pesquisa Humana - UNIFENAS -, sendo aprovados sob o Protocolo número 4.462.761.

\section{Descrição do objeto de estudo}

A pesquisa foi realizada em uma empresa de Holter digital na região do Sul de Minas Gerais, com o objetivo de conhecer a satisfação interna da empresa, como seu clima e as percepções individuais de gestores e de funcionários, enfatizando a importância do fator capital humano na geração de rendimento para instituições.

\section{Delineamento da pesquisa}

Participaram da execução do existente trabalho a orientadora, mestre na área do tema, a qual conduziu a pesquisa. Também houve a atuação das colaboradoras da pesquisa para suporte na atividade de aplicação do questionário de pesquisa de clima. A amostra selecionada contém ao todo 


\section{RECIMA21 - REVISTA CIENTÍFICA MULTIDISCIPLINAR}

CLIMA ORGANIZACIONAL EM UMA MICROEMPRESA DE HOLTER DIGITAL NA REGIÃO DO SUL DE MINAS GERAIS Ana Júlia Melo Prado, Vitória Thainá Siqueira Breves, Sandra de Souza Alves

17 funcionários da empresa, representando $100 \%$ dos colaboradores, os quais participaram do procedimento observatório para fins de compreensão dos resultados dos questionários relatados.

A aplicação do método foi efetuada presencialmente, por meio de um questionário semiestruturado, pesquisa qualitativa e observacional e objetiva sobre o clima organizacional, posicionado estrategicamente para serem logrados pelo departamento de recursos humanos da empresa. Foram preenchidos antes de todos os questionários, o Termo de Consentimento Livre e Esclarecido (TCLE), ficando uma cópia com cada voluntário que respondeu à pesquisa.

\section{Procedimentos específicos adotados}

O trabalho em questão trata-se de uma pesquisa descritiva de caráter Transversal, sendo feita uma análise exploratória de dados.

A pesquisa foi realizada e os dados levantados foram computados e analisados através do software Microsoft Excel e, para nível de entendimento, os referentes fatos foram projetados mediante os gráficos e as tabelas, tornando visível o retorno sobre a pesquisa de clima, tanto para os colaboradores, quanto para os gestores, para que, posteriormente, possam realizar planejamento de aperfeiçoamento.

As variáveis que foram avaliadas na pesquisa de clima organizacional foram as seguintes:

- Relacionamento interpessoal

- Relacionamento chefe/subordinado

- Comunicação interna

- Motivação

- Carreira

- Treinamentos

- Segurança

\section{Análise de dados}

A pesquisa qualitativa observacional foi realizada com o intuito de mensurar como os funcionários sensorialmente estão alocados no ambiente interno da empresa, procurando identificar possíveis fatores importantes que influenciam nos resultados positivos e negativos.

Os dados de cada questão do questionário foram lançados no software Microsoft Excel 2007 . Após esse lançamento, foi calculada, por meio da ferramenta a média de cada variável da pesquisa de clima organizacional e foi feita a análise minuciosa.

A parte inicial do questionário aplicado buscou analisar os dados demográficos dos funcionários para traçar o perfil dos colaboradores, dessa maneira, esclarecendo aspectos pessoais, 


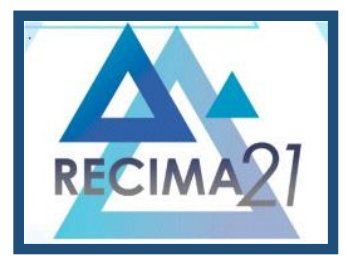

\section{RECIMA21 - REVISTA CIENTÍFICA MULTIDISCIPLINAR}

CLIMA ORGANIZACIONAL EM UMA MICROEMPRESA DE HOLTER DIGITAL NA REGIÃO DO SUL DE MINAS GERAIS Ana Júlia Melo Prado, Vitória Thainá Siqueira Breves, Sandra de Souza Alves

tais como: idade, sexo e escolaridade e características profissionais como, por exemplo, função exercida e tempo de empresa.

Já na segunda parte da pesquisa, foram averiguadas seis variáveis especificamente: relacionamento interpessoal, relacionamento chefe e subordinado, comunicação interna, motivação, carreira, treinamento e segurança, a fim de estipular o contexto atual perante a esfera examinada. Cada pergunta era constituída por quatro opções, sendo estas: sempre, quase sempre, raramente e nunca, variando em decorrência do sentindo proposto. Além de perguntas abertas nas quais os respondentes puderam indicar sugestões e fazer comentários que considerassem solenes a respeito do ambiente organizacional. Com tudo isso, obteve-se o nível de percepção do ambiente interno e fatores marcantes.

\section{RESULTADOS E DISCUSSÃO}

\section{Perfil dos respondentes}

Para caracterizar o perfil dos colaboradores, a primeira pergunta foi destinada a demonstrar a distribuição em relação ao sexo. Ao total de 17 funcionários, 14 são do sexo feminino, o que corresponde a 82,35\% e três são do sexo masculino, representando 17,64\%, conforme o Gráfico 1 .

Gráfico 1 - Sexo dos participantes

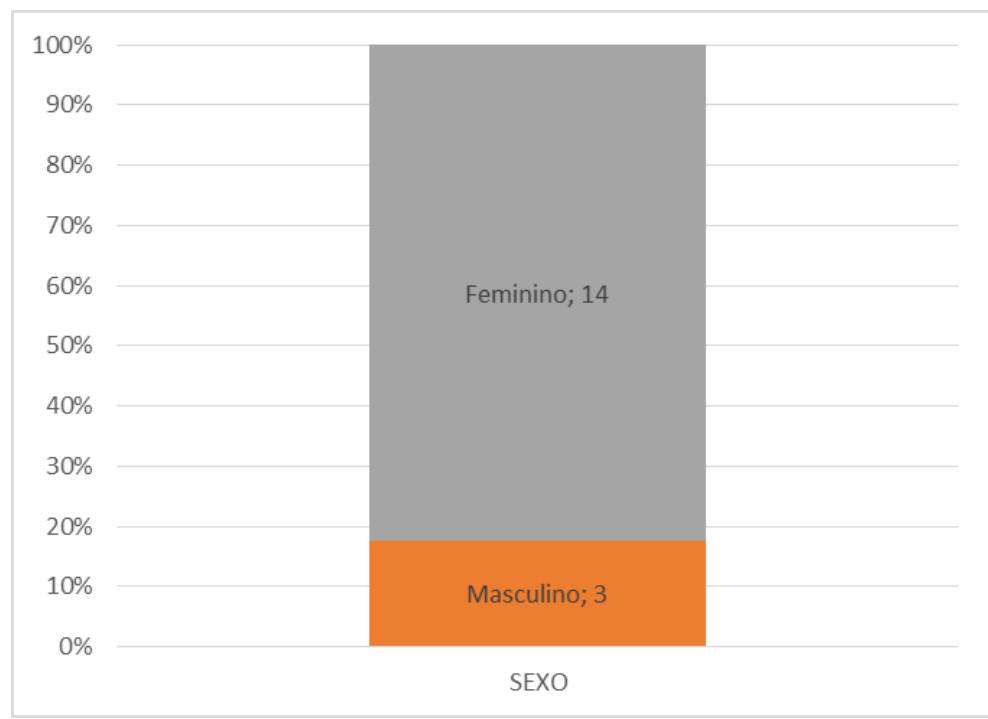

Fonte: Dados da pesquisa (2020) 


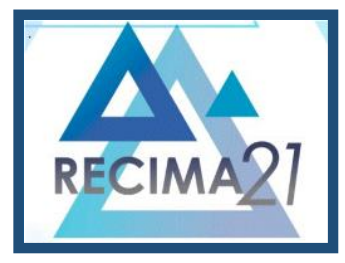

\section{RECIMA21 - REVISTA CIENTÍFICA MULTIDISCIPLINAR}

CLIMA ORGANIZACIONAL EM UMA MICROEMPRESA DE HOLTER DIGITAL NA REGIÃO DO SUL DE MINAS GERAIS Ana Júlia Melo Prado, Vitória Thainá Siqueira Breves, Sandra de Souza Alves

Em relação à escolaridade dos colaboradores da empresa, pode-se observar no Gráfico 2 que os funcionários que possuem apenas o ensino médio representam a maioria, com 63\%; logo em seguida, os com ensino superior e pós-graduação correspondem ao restante da distribuição, com $37 \%$ do total.

Gráfico 2 - Escolaridade dos participantes

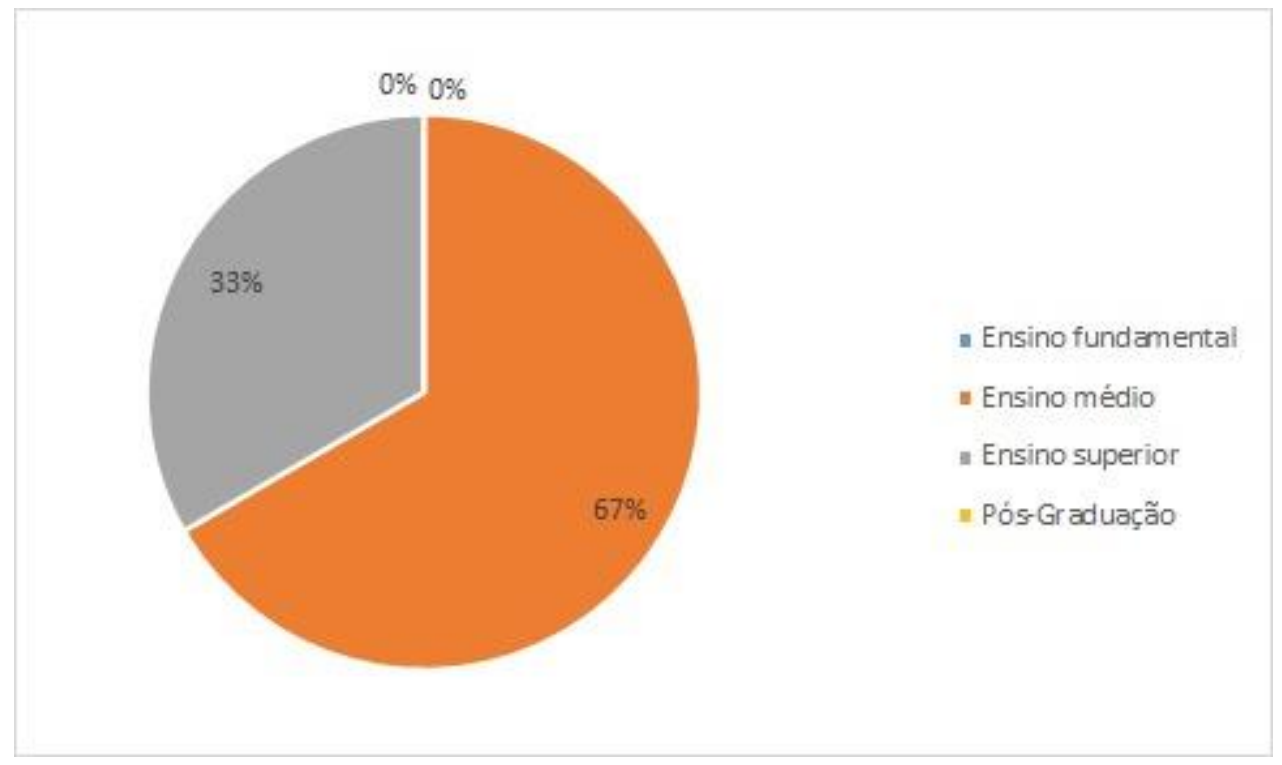

Fonte: Dados da pesquisa (2020)

No que se refere à faixa etária dos respondentes, a maior parte constituída por $58,82 \%$ de pessoas pertencentes ao intervalo de idade de 18 a 31 anos, como demonstrado no Gráfico 3. 


\section{RECIMA21 - REVISTA CIENTÍFICA MULTIDISCIPLINAR}

CLIMA ORGANIZACIONAL EM UMA MICROEMPRESA DE HOLTER DIGITAL NA REGIÃO DO SUL DE MINAS GERAIS Ana Júlia Melo Prado, Vitória Thainá Siqueira Breves, Sandra de Souza Alves

Gráfico 3 - Faixa etária dos funcionários

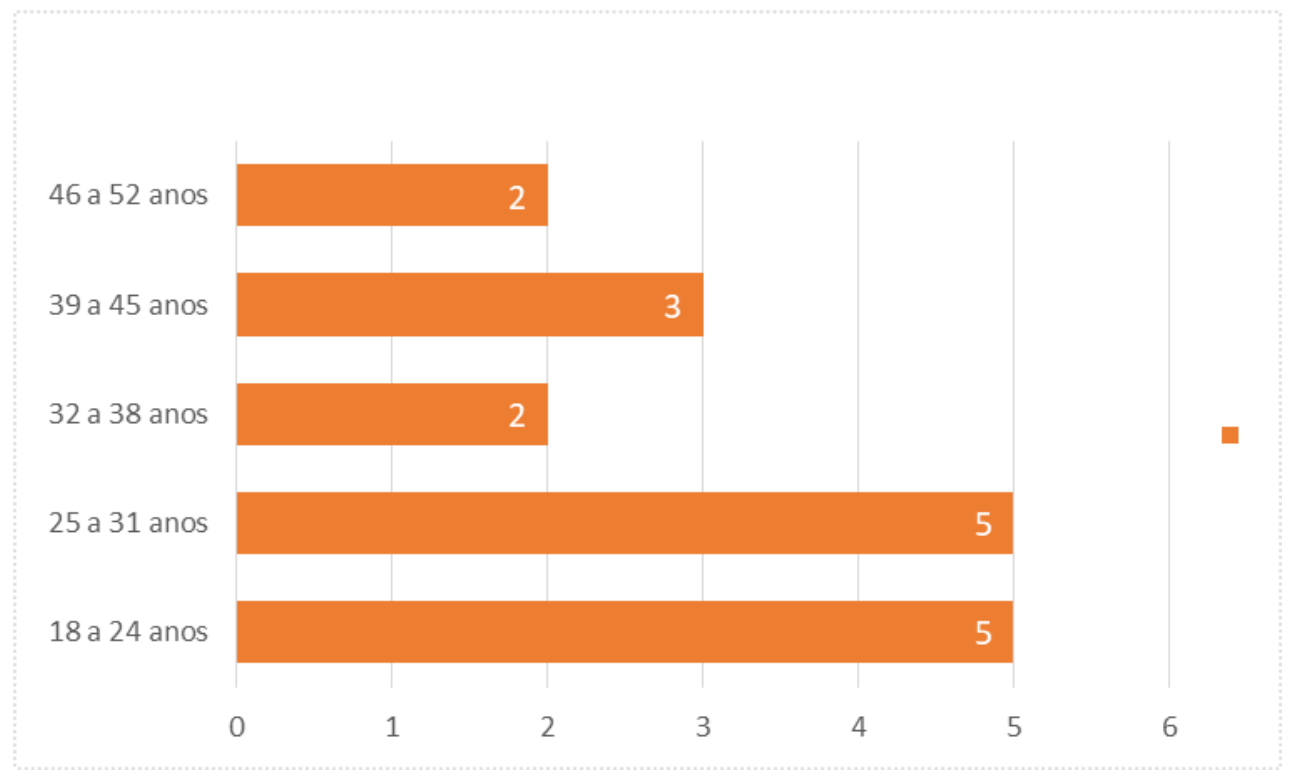

Fonte: Dados da pesquisa (2020)

No que tange ao aspecto tempo de empresa, os funcionários que já estão há mais de 1 ano em atividade equivalem a $64,70 \%$ do total. Isso significa que possuem um período importante de convivência. Ademais, $88,23 \%$ exercem a função pertinente aos serviços operacionais, conforme pode ser observado no Gráfico 4 de análise cruzada.

Gráfico 4 - Relação tempo de empresa e função exercida

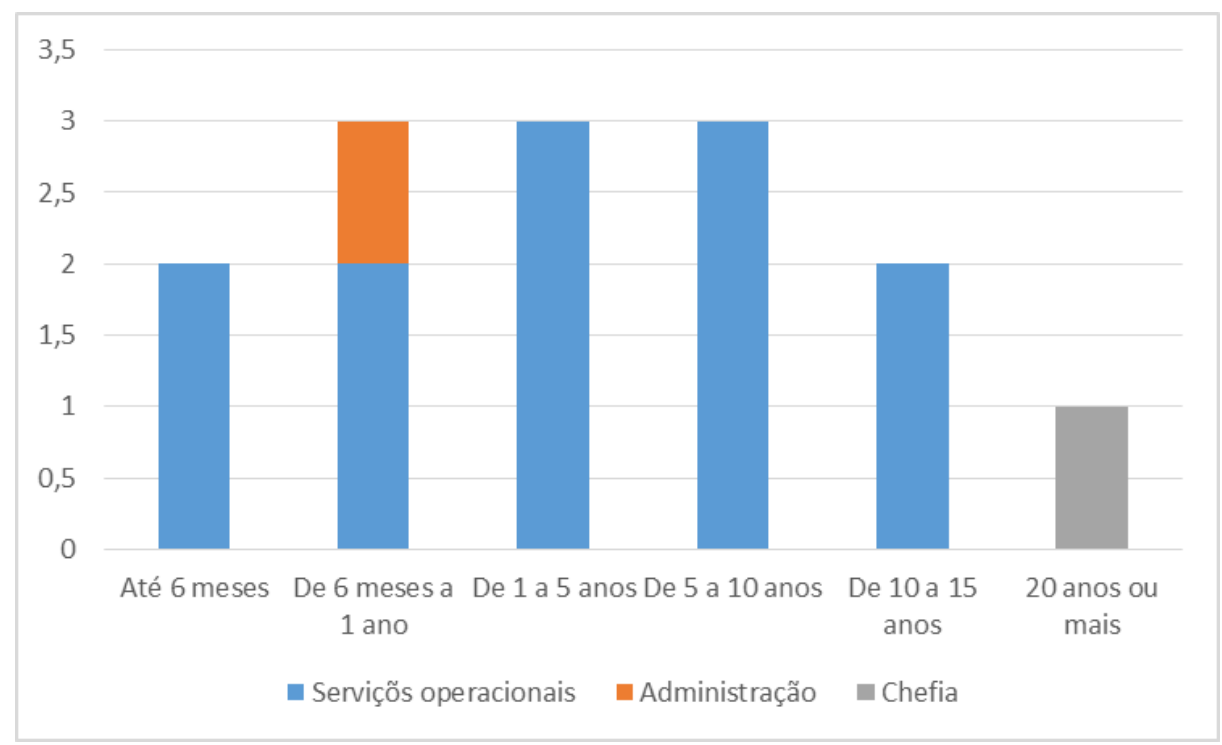




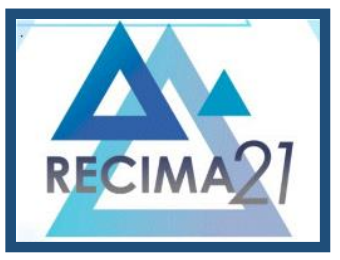

\section{RECIMA21 - REVISTA CIENTÍFICA MULTIDISCIPLINAR}

CLIMA ORGANIZACIONAL EM UMA MICROEMPRESA DE HOLTER DIGITAL NA REGIÃO DO SUL DE MINAS GERAIS Ana Júlia Melo Prado, Vitória Thainá Siqueira Breves, Sandra de Souza Alves

Fonte: Dados da pesquisa (2020).

\section{Variável relacionamento interpessoal}

Conforme o questionário aplicado, foram feitas seis questões concernentes ao relacionamento interpessoal, obtendo um resultado cabal a um nível médio de proficiência correspondente a $91,18 \%$. No entanto, observa-se que o item sobre reuniões periódicas para a captação de novas ideias deixa a desejar em relação aos outros percentuais, ficando abaixo do índice satisfatório de 70\%. Desse modo, foi feita uma análise parcial da questão, em que, no total de dezessete pessoas respondentes, seis $(35 \%)$ responderam que raramente há reuniões para discussões de problemas e sugestões de melhoria, como evidencia o Gráfico 6.

A ocorrência evidencia a importância de se aumentar o brainstorming com o intuito de intensificar a employeevoice, elevando o sentimento de pertencimento e de comprometimento no ambiente de trabalho.

Gráfico 5 - Nível de satisfação no aspecto relacionamento interpessoal

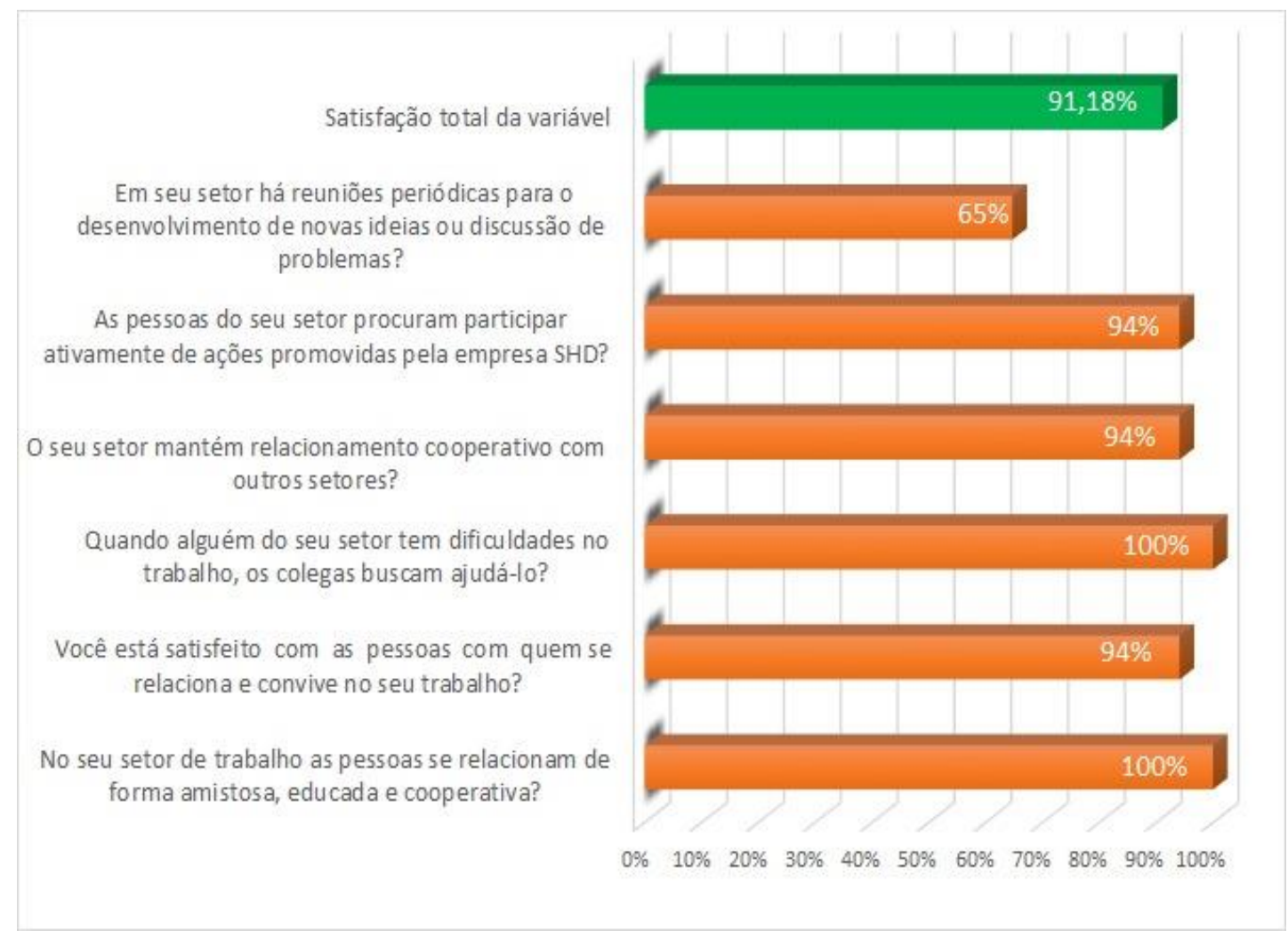

Fonte: Dados da pesquisa (2020) 


\section{RECIMA21 - REVISTA CIENTÍFICA MULTIDISCIPLINAR}

CLIMA ORGANIZACIONAL EM UMA MICROEMPRESA DE HOLTER DIGITAL NA REGIÃO DO SUL DE MINAS GERAIS Ana Júlia Melo Prado, Vitória Thainá Siqueira Breves, Sandra de Souza Alves

Gráfico 6 - Pergunta relacionada à periodicidade de reuniões

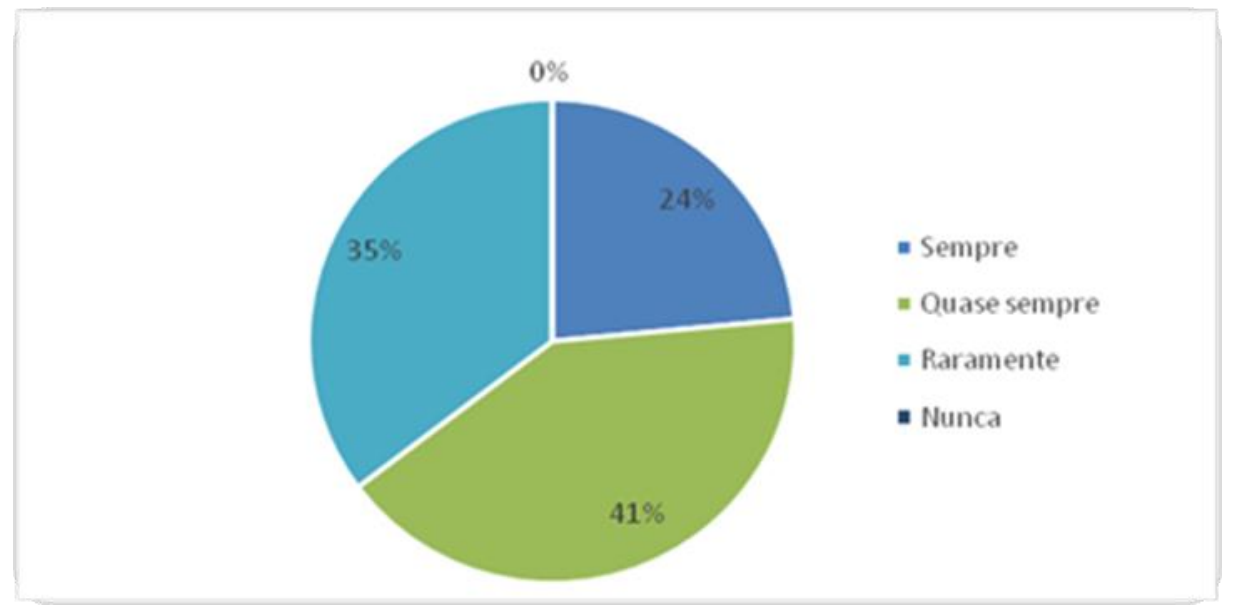

Fonte: Dados da pesquisa (2020)

\section{Variável relacionamento chefe e subordinado}

Em relação ao relacionamento chefe e subordinado, a variável aponta um nível de satisfação relevante, alcançando o patamar médio de 97,06\%, um índice maior em comparação com a situação do aspecto relacionamento interpessoal. As concepções dos funcionários, diante da ação da gerência, é uma característica substancial, como já citado no referencial teórico, pois promove interações sinérgicas que aumentam o envolvimento e o desenvolvimento por parte dos colaboradores devido a ações advindas de fatores qualitativos do suporte gerencial, o que implica maior rendimento dentro do ambiente organizacional (SUNG \& CHOI, 2014).

Diante das circunstâncias dos dados do questionário sobre essa seção é possível verificar que os funcionários aprovam a maneira como são conduzidas as resoluções de problemas e como é dada a acessibilidade para a construção de alternativas frente a contingências operacionais e à atenção ao grau de desenvolvimento da equipe, em aspectos gerais. O Gráfico 7 demonstra, em porcentagem, a aprovação do relacionamento entre chefia e subordinado. 


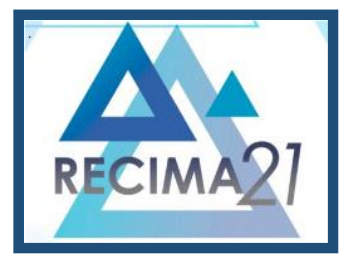

\section{RECIMA21 - REVISTA CIENTÍFICA MULTIDISCIPLINAR}

CLIMA ORGANIZACIONAL EM UMA MICROEMPRESA DE HOLTER DIGITAL NA REGIÃO DO SUL DE MINAS GERAIS

Ana Júlia Melo Prado, Vitória Thainá Siqueira Breves, Sandra de Souza Alves

Gráfico 7 - Nível de satisfação no aspecto relacionamento Chefe e Subordinado

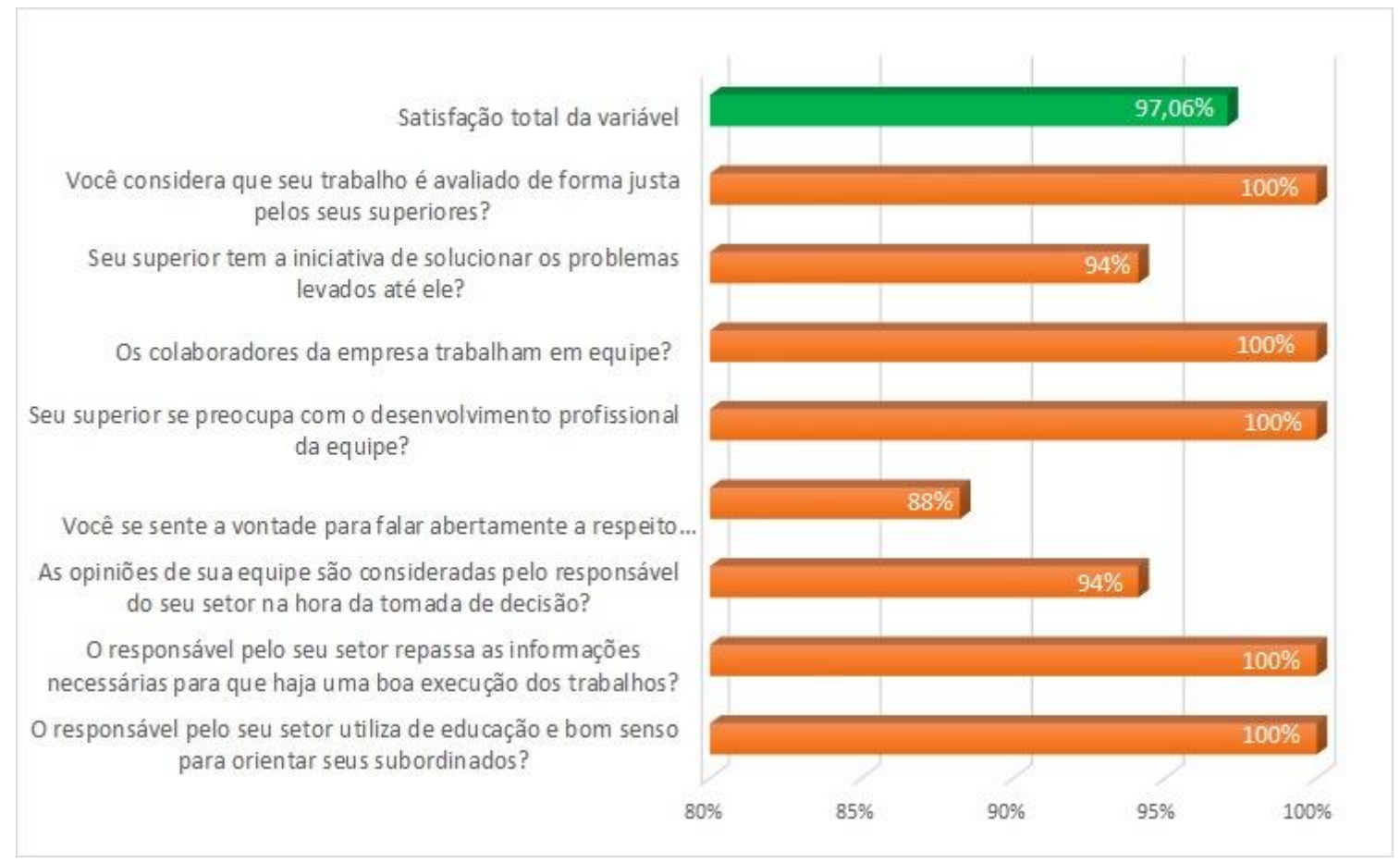

Fonte: Dados da pesquisa (2020)

\section{Variável comunicação interna}

A comunicação, como já citado na teoria, está envolvida com a melhora contínua de qualidade de desempenho, o qual possui uma parcela relevante na desenvoltura do funcionário. Para determinar o nível de comunicação interna da empresa, realizou-se uma avaliação por meio de duas perguntas objetivas e uma aberta.

O resultado se mostrou convincente por efeito da taxa de aceitação média em torno de $97,06 \%$. Nas questões objetivas, os funcionários demonstraram consentir com a maneira de como toda a informação é repassada com objetividade, além de regularmente obterem transparência, por parte da chefia, dos acontecimentos relevantes. O canal de comunicação da empresa usualmente é por meio de reuniões periódicas ou por ligações, que por via de resposta de um funcionário na pergunta aberta, decorre no surgimento de alguma adversidade no ambiente, o que reforça a informação obtida por meio do gráfico 5 , em que o nível de satisfação em relação ao espaço aberto a comunicação foi abaixo do nível ideal (70\%). O Gráfico 8 , a seguir, resume a situação atual da comunicabilidade. 


\section{RECIMA21 - REVISTA CIENTÍFICA MULTIDISCIPLINAR}

CLIMA ORGANIZACIONAL EM UMA MICROEMPRESA DE HOLTER DIGITAL NA REGIÃO DO SUL DE MINAS GERAIS

Ana Júlia Melo Prado, Vitória Thainá Siqueira Breves, Sandra de Souza Alves

Gráfico 8 - Nível de comunicação interna

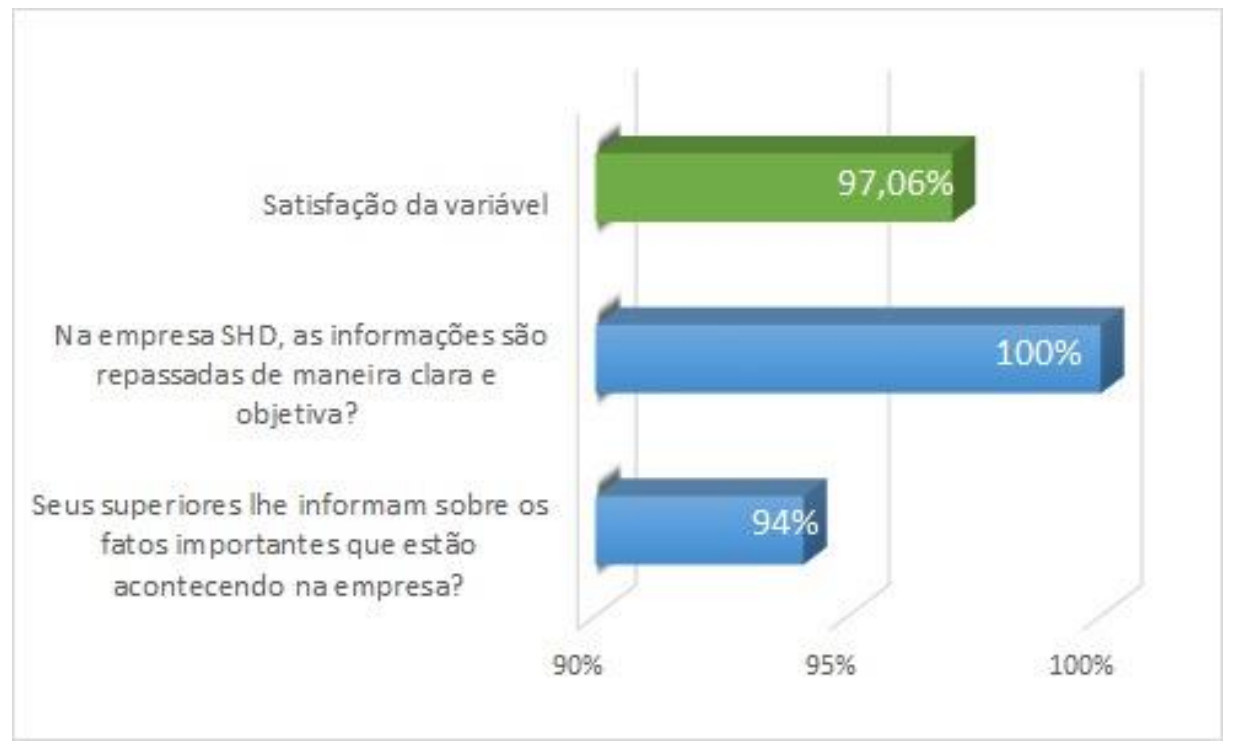

Fonte: Dados da pesquisa (2020)

\section{Variável motivação}

A motivação dos funcionários da empresa foi mensurada por meio de cinco perguntas objetivas, obtendo uma média de satisfação de 90,59\%, o que aponta que os aspectos intrínsecos estão em conformidade com o que se manifesta. A variável analisada é uma propriedade substancial eminente as percepções subjetivas, o que acaba por influenciar o comportamento.

Os dados obtidos mostram que os elementos quantitativos, remuneração, e qualitativos, em relação ao aperfeiçoamento profissional, se mostraram aprazíveis, obtendo uma porcentagem maior que $80 \%$, um índice bastante aceitável. No entanto, ao perguntar sobre a possibilidade de crescimento profissional, o índice de pessoas que desacreditam na viabilidade foi maior em comparação ao aspecto analisado, ou seja, é um ponto a ser estudado por se direcionará estrutura hierarquia, a qual é limitada por ser uma microempresa sem plano de carreira horizontal.

Os gráficos a seguir mostram a distribuição, em porcentagem, tanto da pergunta parcial (Gráfico 9) quanto da análise geral realizada (Gráfico 10). 


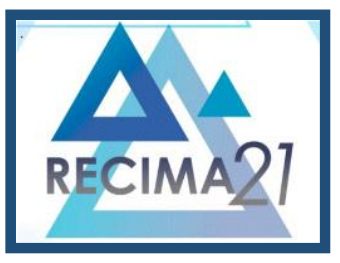

\section{RECIMA21 - REVISTA CIENTÍFICA MULTIDISCIPLINAR}

CLIMA ORGANIZACIONAL EM UMA MICROEMPRESA DE HOLTER DIGITAL NA REGIÃO DO SUL DE MINAS GERAIS Ana Júlia Melo Prado, Vitória Thainá Siqueira Breves, Sandra de Souza Alves

Gráfico 9 - Opinião em relação possibilidade de crescimento profissional

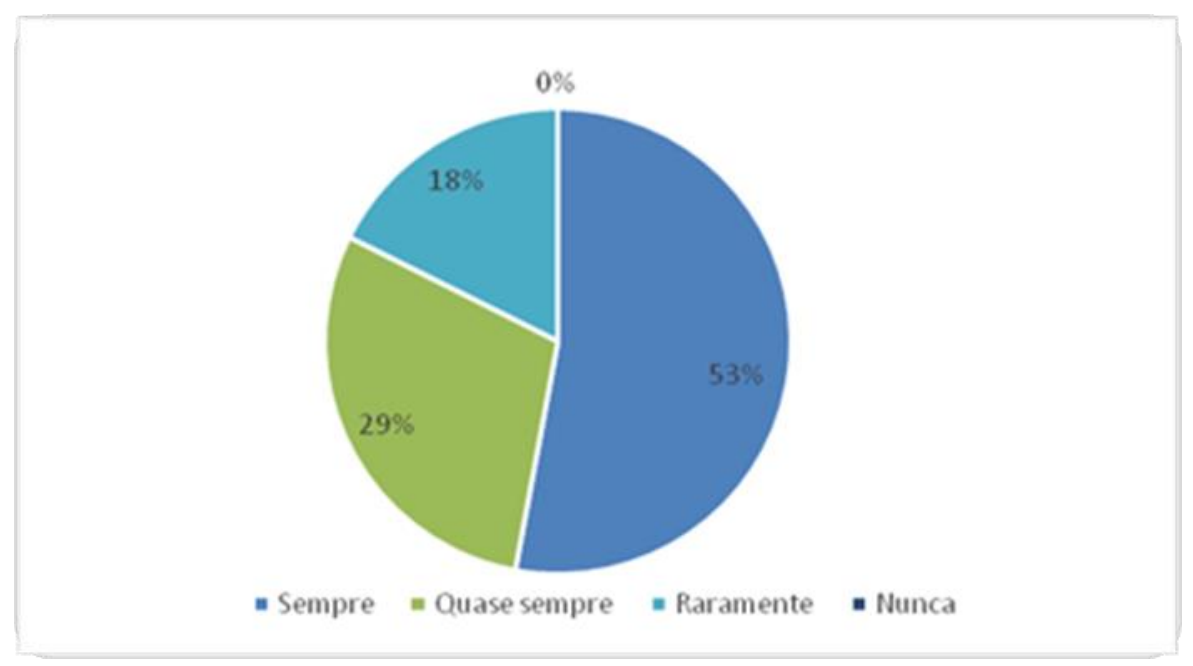

Fonte: Dados da pesquisa (2020)

Gráfico 10 - Nível geral de motivação

Nível total de satisfação da variável

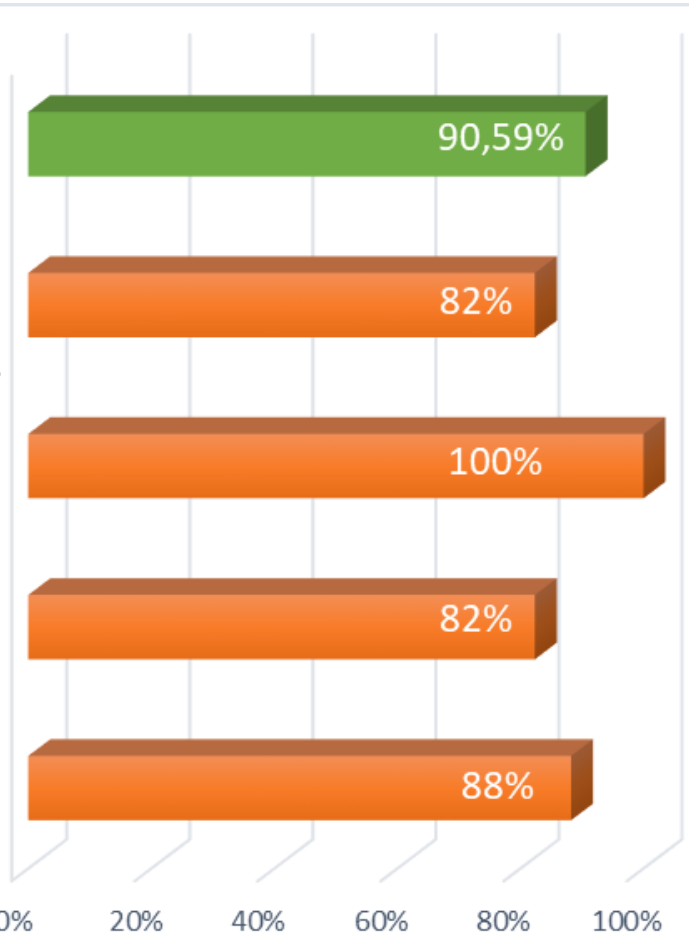

Fonte: Dados da pesquisa (2020) 


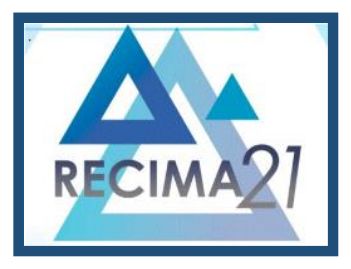

\section{RECIMA21 - REVISTA CIENTÍFICA MULTIDISCIPLINAR}

CLIMA ORGANIZACIONAL EM UMA MICROEMPRESA DE HOLTER DIGITAL NA REGIÃO DO SUL DE MINAS GERAIS

Ana Júlia Melo Prado, Vitória Thainá Siqueira Breves, Sandra de Souza Alves

\section{Variável carreira}

O nível de satisfação da variável carreira foi estimulado por meio de quatro perguntas objetivas, obtendo uma média de $89,61 \%$. No geral, os colaboradores da empresa estão em concordância perante a metodologia do ofício praticado no local, obtendo um nível satisfatório recomendado, ou seja, maior que $70 \%$, como exposto no gráfico 10 a seguir.

No entanto, há algumas considerações a serem feitas em relação à expectativa de crescimento profissional em conformidade com a implantação de porcentagem de vendas. Apesar de atingir a sugestão mínima para alacridade, foi a resposta com o nível mais baixo em comparação com as outras questões da seção. O Gráfico 11 demonstra que, do total de 17 pessoas que responderam à pergunta referente, 3 pessoas (17\%) não possuem certeza de crescimento profissional diante da implantação de meta de vendas; 1 pessoa (6\%) não tem expectativa e 3 pessoas (18\%) não souberam opinar, o que solidifica a incerteza diante da possível operação.

Gráfico 11 - Nível de satisfação em carreira

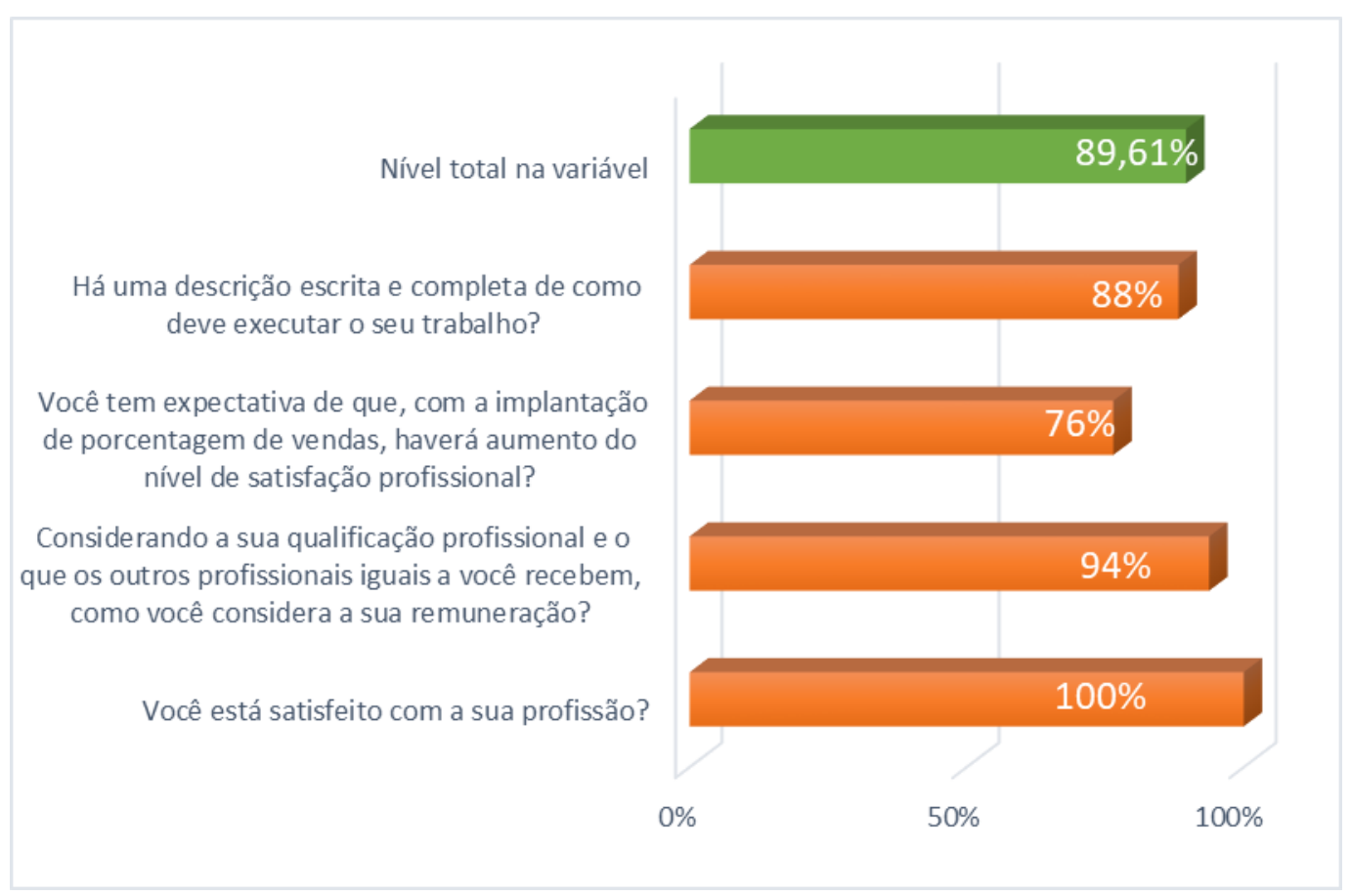

Fonte: Dados da pesquisa (2020) 


\section{RECIMA21 - REVISTA CIENTÍFICA MULTIDISCIPLINAR}

CLIMA ORGANIZACIONAL EM UMA MICROEMPRESA DE HOLTER DIGITAL NA REGIÃO DO SUL DE MINAS GERAIS

Ana Júlia Melo Prado, Vitória Thainá Siqueira Breves, Sandra de Souza Alves

Gráfico 12 - Opinião em relação à possibilidade de satisfação profissional mediante a implantação de porcentagem de vendas.

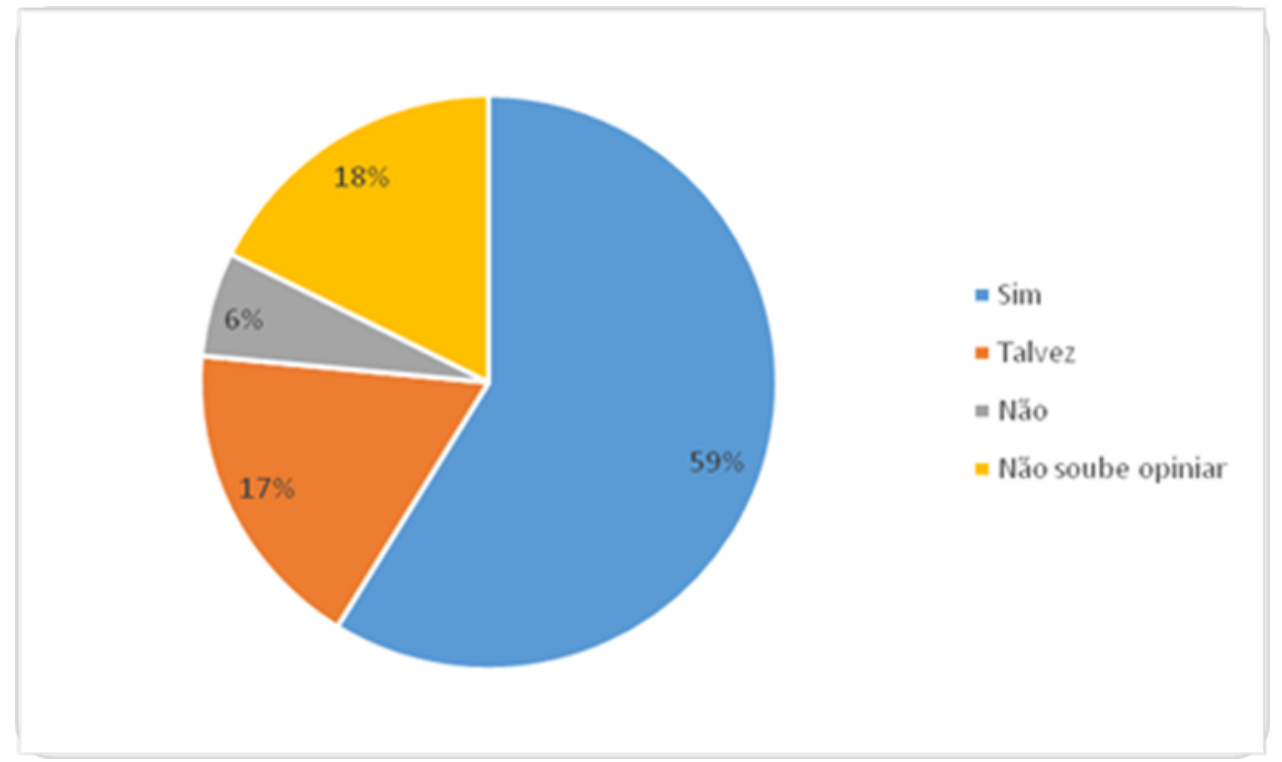

Fonte: Dados da pesquisa (2020)

\section{Variável treinamento}

O desenvolvimento humano na organização é fundamental para aperfeiçoar as qualidades de um funcionário, capacitando-o para resolver problemas cotidianos de forma inovadora, o que torna importante a implantação conjunta de treinamentos metodológicos. De acordo com Peloso e Yonemoto (2010) e Chiavenato (2014), o treinamento é um artifício de gestão para dar eficácia e eficiência, condensando objetivos do negócio para a mesma vertente.

O resultado do nível de satisfação em treinamento de $87,99 \%$ foi medido por intermédio de três perguntas objetivas. Em concordância com as informações expostas do Gráfico 12 é possível observar que a concepção dos funcionários diante das questões levantadas se mostrou positiva, ou seja, a multiplicidade aprova a qualidade e o direcionamento das capacitações desenvolvidas em prol da melhoria da prestação de serviços, mesmo na presença de casos isolados que não souberam responder e não concordam de alguma maneira com a aplicabilidade das capacitações. O Gráfico 13 mostra a porcentagem das respostas para cada alternativa. 


\section{RECIMA21 - REVISTA CIENTÍFICA MULTIDISCIPLINAR}

CLIMA ORGANIZACIONAL EM UMA MICROEMPRESA DE HOLTER DIGITAL NA REGIÃO DO SUL DE MINAS GERAIS Ana Júlia Melo Prado, Vitória Thainá Siqueira Breves, Sandra de Souza Alves

Gráfico 13 - Nível de satisfação em treinamento

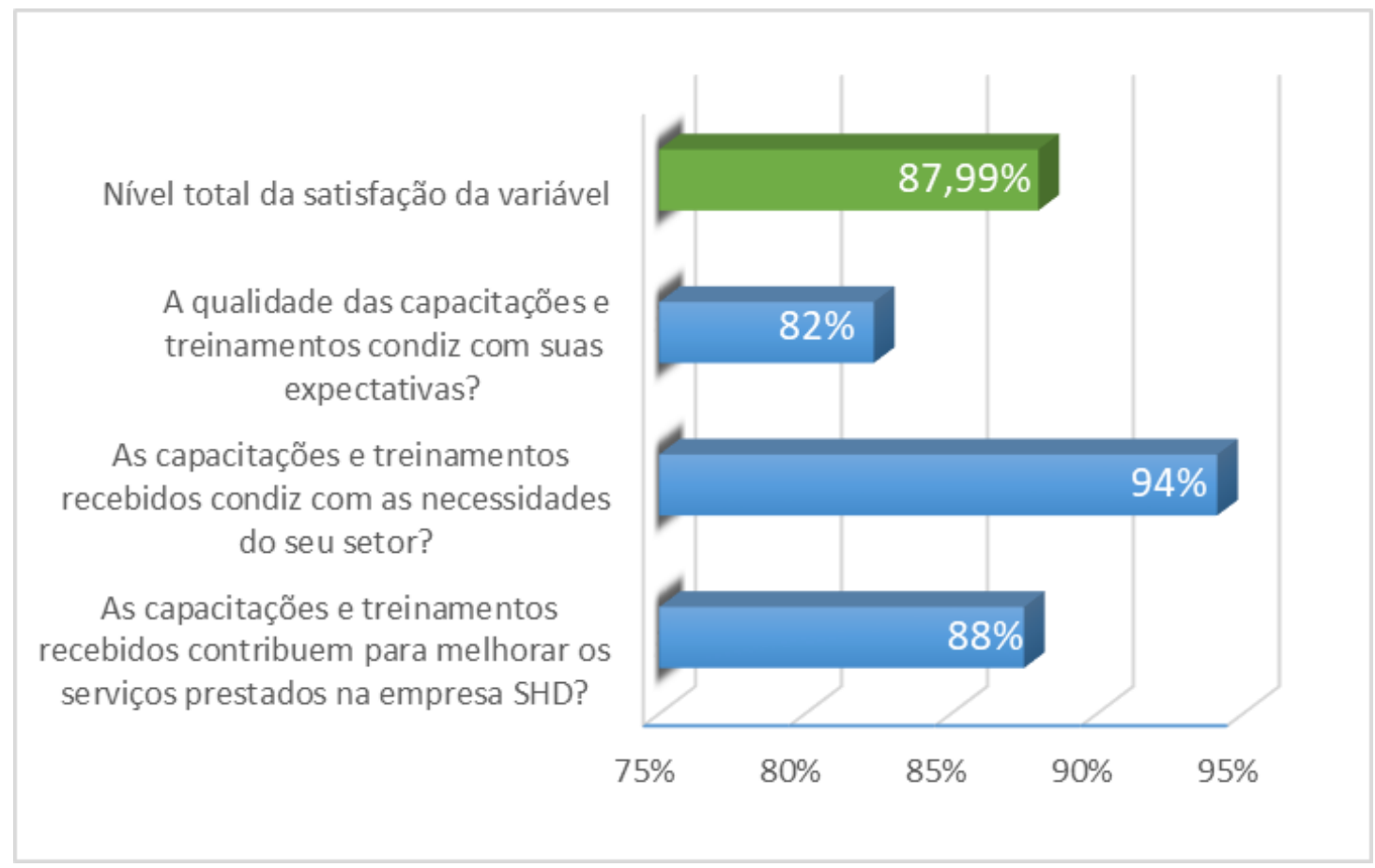

Fonte: Dados da pesquisa (2020)

\section{Variável segurança}

Neste ponto foram analisadas as opiniões dos funcionários em relação às condições do ambiente de trabalho. A seção foi dividida em duas perguntas objetivas, três perguntas destinadas a pontuar tópicos relacionados à estrutura do ambiente de trabalho e indicações de pontos que causam satisfação e insatisfação, além de uma questão aberta parar efetuar sugestões e comentários, levando em consideração que não foram todos os funcionários que opinaram.

O nível médio de satisfação da variável foi de 97,46\%, como exposto no Gráfico 14. Em uma análise crítica, o ambiente estrutural se mostra adequado para o cumprimento das funções estabelecidas, sendo necessária uma análise isolada de alguns casos. 


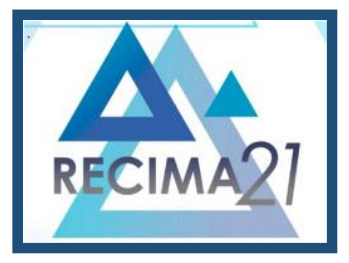

\section{RECIMA21 - REVISTA CIENTÍFICA MULTIDISCIPLINAR}

CLIMA ORGANIZACIONAL EM UMA MICROEMPRESA DE HOLTER DIGITAL NA REGIÃO DO SUL DE MINAS GERAIS Ana Júlia Melo Prado, Vitória Thainá Siqueira Breves, Sandra de Souza Alves

Gráfico 14 - Nível de satisfação em segurança

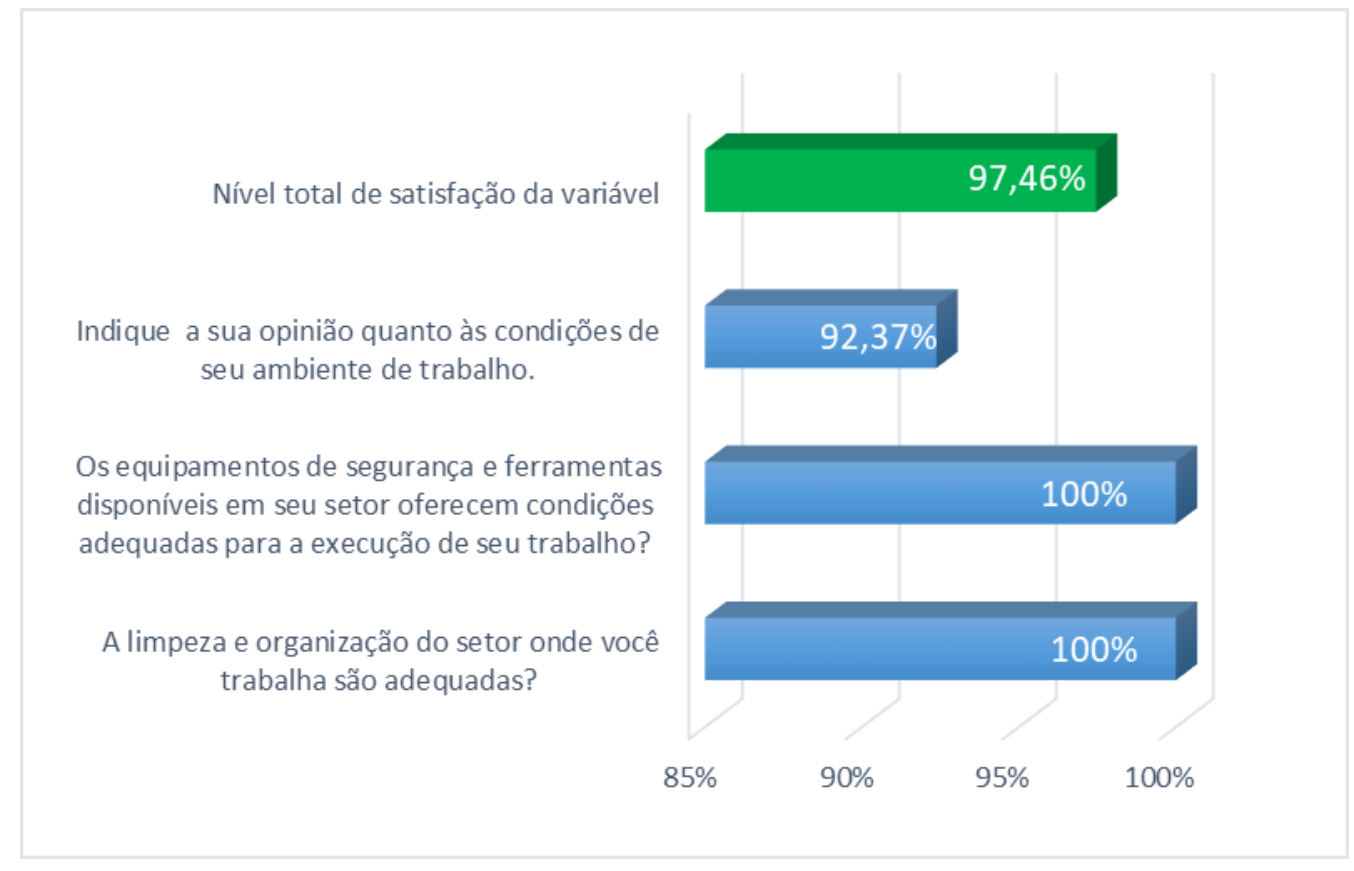

Fonte: Dados da pesquisa (2020)

Outro ponto a ser listado relaciona-se às razões que causam maior contentamento aos funcionários, que foram os quesitos salário e, logo após, o reconhecimento, como demonstrado no Gráfico 15. Ou seja, dois aspectos de natureza distinta, fator quantitativo e qualitativo, mas que se interligam ao gerar maior envolvimento das partes. Todavia, ao serem questionados sobre pontos que geram contrariedade, o resultado obtido foi: impossibilidade de crescimento profissional e instalações inadequadas, como visto no Gráfico 16. Em relação ao último ponto, a falta de iluminação de emergência e a não divisão das salas por função exercida atrapalham na concentração, de acordo com o comentário da questão aberta. Além desse comentário, outro funcionário ponderou que o espírito de equipe entre os funcionários não é exercido de maneira plena. 


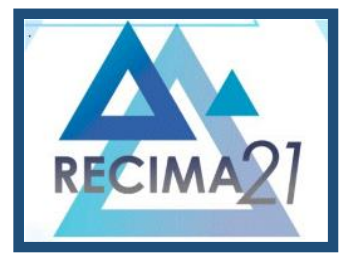

\section{RECIMA21 - REVISTA CIENTÍFICA MULTIDISCIPLINAR}

CLIMA ORGANIZACIONAL EM UMA MICROEMPRESA DE HOLTER DIGITAL NA REGIÃO DO SUL DE MINAS GERAIS Ana Júlia Melo Prado, Vitória Thainá Siqueira Breves, Sandra de Souza Alves

Gráfico 15 - Fatores mais motivadores Gráfico 16 - Fatores menos motivadores

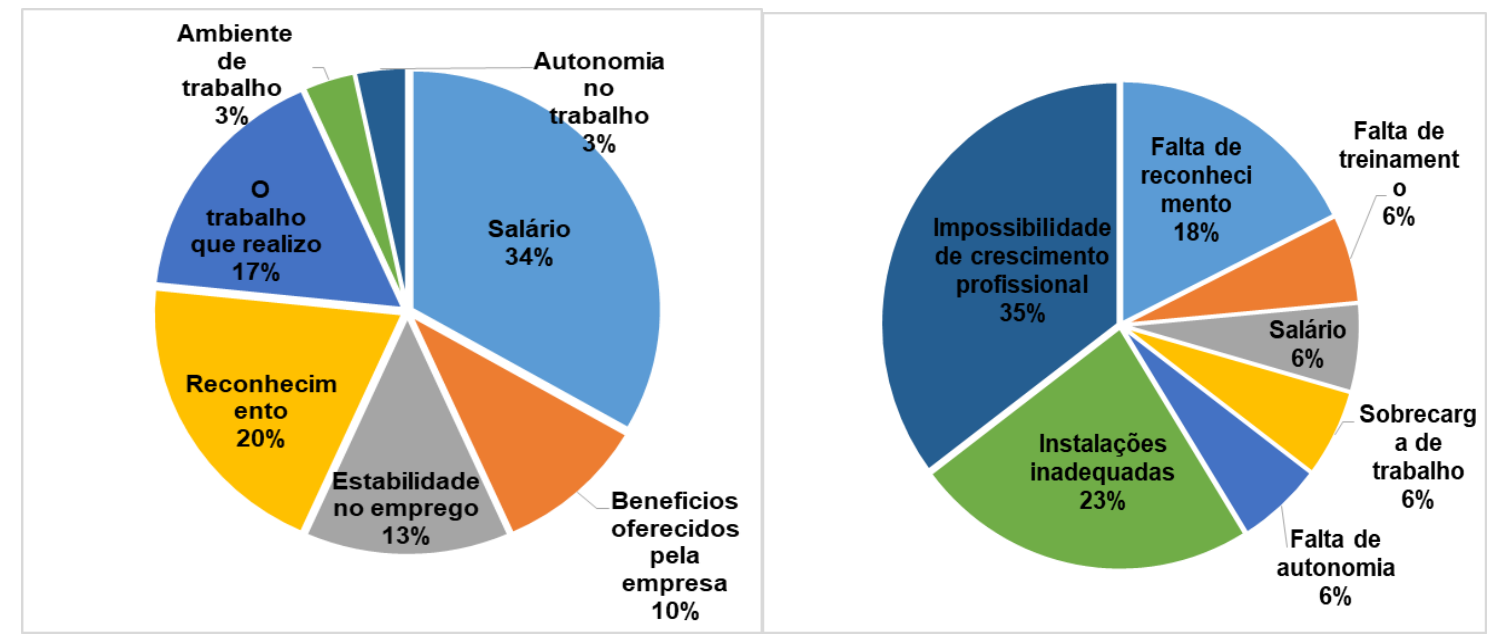

Fonte: Dados da pesquisa (2020)

Fonte: Dados da pesquisa (2020)

\section{Resultado da satisfação em nível geral}

Após realizar uma análise dos dados coletados, pode-se afirmar que a empresa apresenta um clima organizacional favorável, diante do cálculo das médias de todas as variáveis examinadas, obtendo-se, em nível geral, um porcentual de 92,99\%. A quantidade pequena de funcionários é um ponto a ser levado em consideração, o que significa que o ambiente é mais fácil de ser estimulado, porém não remete à inexistência de problemas. Em algumas partes, percebe-se a presença de alguns "gaps" vinculados a um espaço mais aberto às sugestões e ao trabalho em equipe com a inclusão da percepção de crescimento profissional bastante ilimitado e o fator treinamento, o qual obteve a porcentagem mais baixa $(87,99 \%)$ em relação às outras variáveis analisadas, colocando em pauta que esses aspectos são sinérgicos ao bom desenvolvimento dos Recursos Humanos e ao desenvolvimento humano. Mas, no completo, as ocorrências não chegaram a comprometer com potencialidade o resultado. Por conseguinte, o objetivo do estudo foi atingindo, uma vez que foram estudados assuntos relacionados ao tema, dando suporte à mensuração e à análise dos dados coletados.

\section{CONCLUSÃO}

O clima organizacional é de grande valia dentro de uma organização. Por meio da percepção desse fator é cabível aos setores estratégicos implantar ações, a fim de obter melhoras significativas no ambiente interno, promovendo eficiência operacional. Conseguintemente, os 


\section{RECIMA21 - REVISTA CIENTÍFICA MULTIDISCIPLINAR}

CLIMA ORGANIZACIONAL EM UMA MICROEMPRESA DE HOLTER DIGITAL NA REGIÃO DO SUL DE MINAS GERAIS Ana Júlia Melo Prado, Vitória Thainá Siqueira Breves, Sandra de Souza Alves

setores externos podem ser influenciados pela boa gestão do recurso humano, gerando vantagem competitiva.

Atentando para isso, o desfecho da análise do presente estudo demonstrou que a percepção dos gestores e dos colaboradores com relação às práticas de gestão e aos relacionamentos no ambiente de trabalho da microempresa de holter digital são bastante pertinentes ao finalizar a ponderação das variáveis participantes do conceito.

A partir dos resultados obtidos, pode-se concluir que a maioria dos funcionários está no nível de satisfação geral de 92,25\%, apontando que se sentem confortáveis com o clima da organização, principalmente nas variáveis de relacionamento entre chefe e subordinado, comunicação interna e relacionamento interpessoal.

Mesmo com altos níveis de satisfação em todas as variáveis, há alguns pontos estratégicos a serem analisados isoladamente, pois apresentaram indicadores mais atilados em comparação aos demais fatores, sendo estes: a motivação, a carreira e o treinamento. É conveniente solicitude da organização nesses fatores para a elaboração de um plano de procedimento em longo prazo.

Inclusive, vale ressaltar que, embora seja uma temática recorrente aos assuntos atuais em administração, o clima organizacional possui um papel importante para impulsionar o envolvimento e o desempenho dos colaboradores mediante a adoção de política de desenvolvimento em Recursos Humanos, a qual implica dimensões quantitativas e qualitativas.

\section{REFERÊNCIAS}

ALEXANDRE, Mayara. Pesquisa de clima organizacional: um estudo de caso. $\mathbf{e}^{3}$ - Revista de Economia, Empresas e Empreendedores na CPLP, Portugal, v. 4, n. 1, p. 39-54, jun. 2018.

BEYER, Anne Louise; SOLER, Rodrigo Diaz de Vivar y. O capital humano nas organizações: uma revisão bibliográfica. CIPPUS- Revista de Iniciação Científica, Canoas, v. 7, n. 1, p. 45-52, maio 2019.

CHIAVENATO, Idalberto. Gerenciando com as pessoas: transformando o executivo em um excelente gestor de pessoas. 5. ed. São Paulo: Manole, 2015.

CHIAVENATO, Idalberto. Treinamento e Desenvolvimento de Recursos humanos. 7. ed. São Paulo: Manole, 2015.

DESSLER, Gary. Administração de Recursos Humanos. 2. ed. São Paulo: Pearson Prentice Hall, 2003.

DIAS, Carolina Aparecida de Freitas. Desenvolvimento estratégico de recursos humanos e suas relações com o desempenho organizacional: uma análise dos fatores contingenciais. Disponível em: https://teses.usp.br/teses/disponiveis/12/12139/tde-08012018-122932/pt-br.php. Acesso em: 04. jun. 2020.

JACOBSEN, Alessandra de Linhares; Moretto Neto, Luis. Teoria da Administração II. 3 ed. São Paulo: Capes: UAB, 2015. 


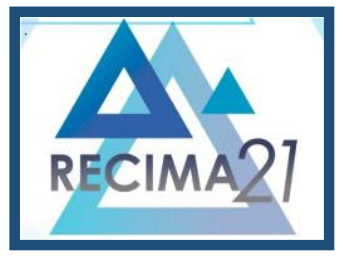

\section{RECIMA21 - REVISTA CIENTÍFICA MULTIDISCIPLINAR}

CLIMA ORGANIZACIONAL EM UMA MICROEMPRESA DE HOLTER DIGITAL NA REGIÃO DO SUL DE MINAS GERAIS

Ana Júlia Melo Prado, Vitória Thainá Siqueira Breves, Sandra de Souza Alves

JOHANN, Silvio Luiz. Comportamento organizacional: teoria e pratica. São Paulo: Saraiva, 2013.

MATOS, Denise Pires. Teorias administrativas e organização do trabalho: de Taylor aos dias atuais, influências no setor saúde e na enfermagem. Texto \& Contexto - Enfermagem, Florianópolis, v. 15, n. 3, jul./set. 2006.

MEZA, Alfredo Montoya Meza. Relación entre el clima organizacional y laevaluación del desempeño del personalen una empresa de servicios turísticos: caso ptsperú 2015. Disponível em: http://tesis.pucp.edu.pe/repositorio/handle/20.500.12404/7490. Acesso em: 01. jul. 2020.

MOREIRA, Fabiano Greter; VIOLIN, Fábio Luciano; SILVIA, Luciana Codognoto. Capital intelectual como vantagem competitiva: um estudo bibliográfico. Recape-Revista de carreiras e pessoas, São Paulo, v. 4, n. 3, p. 296-311, set./out./nov./dez. 2014.

MCKEOWN, Greg. Essencialismo. Tradução: Beatriz Medina. Rio de Janeiro: Sextante, 2015.

PALOMBINO PRIMO, Paschoal; OLIVA, Eduardo de Camargo; KUBO, Edson Keyso de Miranda. Gestão estratégica de pessoas para pesquisadores em nas universidades. READ-Revista eletrônica de administração, Porto Alegre, v. 20, n. 2, maio/ago. 2014.

PASBAN, Mohammad; NOJEDEH, SadeghehHosseinzadeh. A Review of the Role of Human Capital in the Organization, Procedia-Social and Behavioral Sciences, Dubai, v. 230, n. 15, p. 249-253, set. 2016.

PELOSO, Ayslan Cavalcante; YONEMOTO, Hiroshi Wilson. Atração, desenvolvimento e retenção de talentos. ETIC-Encontro de iniciação científica, v. 6, n. 6, 2010.

SIFUENTES, Thirza Reis; DESSEN, Maria Auxiliadora; OLIVEIRA, Maria Cláudia Santos Lopes de. Desenvolvimento humano: desafios para a compreensão das trajetórias probabilísticas. Psicologia: Teoria e Pesquisa, Brasília, v. 23, n. 4, out./dez. 2007.

SIQUEIRA, Mirlene Maria Matias. Medidas do Comportamento Organizacional: Ferramentas de Diagnóstico e de Gestão. Porto Alegre: Artmed, 2008.

STADLER, Adriano; PAMPOLINI, Cláudia Patrícia Garcia. Gestão de pessoas: ferramentas estratégicas de competitividade. Curitiba: Intersaberes, 2014.

SUNG, Sun Young; $\mathrm{CHOI}$, Jin Nam. Multiple dimensions of human resource development and organizational performance. Journal of Organizational Behavior, China, v. 35, n. 6, p. 851-870, abr. 2014. 